Louisiana State University

LSU Digital Commons

Faculty Publications

Department of Chemistry

3-13-2017

\title{
Synthesis and Characterization of Well-Defined PEGylated Polypeptoids as Protein-Resistant Polymers
}

\author{
Sunting Xuan \\ Macromolecular Studies Group \\ Sudipta Gupta \\ Macromolecular Studies Group \\ Xin Li \\ Macromolecular Studies Group \\ Markus Bleuel \\ National Institute of Standards and Technology \\ Gerald J. Schneider \\ Macromolecular Studies Group
}

See next page for additional authors

Follow this and additional works at: https://digitalcommons.Isu.edu/chemistry_pubs

\section{Recommended Citation}

Xuan, S., Gupta, S., Li, X., Bleuel, M., Schneider, G., \& Zhang, D. (2017). Synthesis and Characterization of Well-Defined PEGylated Polypeptoids as Protein-Resistant Polymers. Biomacromolecules, 18 (3), 951-964. https://doi.org/10.1021/acs.biomac.6b01824

This Article is brought to you for free and open access by the Department of Chemistry at LSU Digital Commons. It has been accepted for inclusion in Faculty Publications by an authorized administrator of LSU Digital Commons.

For more information, please contact ir@lsu.edu. 
Authors

Sunting Xuan, Sudipta Gupta, Xin Li, Markus Bleuel, Gerald J. Schneider, and Donghui Zhang 
Subscriber access provided by UB + Fachbibliothek Chemie | (FU-Bibliothekssystem)

\section{Article}

\section{Synthesis and Characterization of Well-defined PEGylated Polypeptoids as Protein-resistant Polymers}

Sunting Xuan, Sudipta Gupta, Xin Li, Markus Bleuel, Gerald J. Schneider, and Donghui Zhang

Biomacromolecules, Just Accepted Manuscript • DOI: 10.1021/acs.biomac.6b01824 • Publication Date (Web): 06 Feb 2017

Downloaded from http://pubs.acs.org on February 7, 2017

\section{Just Accepted}

"Just Accepted" manuscripts have been peer-reviewed and accepted for publication. They are posted online prior to technical editing, formatting for publication and author proofing. The American Chemical Society provides "Just Accepted" as a free service to the research community to expedite the dissemination of scientific material as soon as possible after acceptance. "Just Accepted" manuscripts appear in full in PDF format accompanied by an HTML abstract. "Just Accepted" manuscripts have been fully peer reviewed, but should not be considered the official version of record. They are accessible to all readers and citable by the Digital Object Identifier (DOI®). "Just Accepted" is an optional service offered to authors. Therefore, the "Just Accepted" Web site may not include all articles that will be published in the journal. After a manuscript is technically edited and formatted, it will be removed from the "Just Accepted" Web site and published as an ASAP article. Note that technical editing may introduce minor changes to the manuscript text and/or graphics which could affect content, and all legal disclaimers and ethical guidelines that apply to the journal pertain. ACS cannot be held responsible for errors or consequences arising from the use of information contained in these "Just Accepted" manuscripts. 


\section{Synthesis and Characterization of Well-defined PEGylated Polypeptoids as Protein-} resistant Polymers

Sunting Xuan, ${ }^{1}$ Sudipta Gupta, ${ }^{1}$ Xin Li, ${ }^{1}$ Markus Bleuel, ${ }^{3}$ Gerald J. Schneider ${ }^{1,2 *}$ and Donghui Zhang ${ }^{1 *}$

${ }^{1}$ Department of Chemistry and Macromolecular Studies Group, Louisiana State University, Baton Rouge, LA 70803, USA

${ }^{2}$ Department of Physics, Louisiana State University, Baton Rouge, LA 70803, USA

${ }^{3}$ NIST Center for Neutron Research, National Institute of Standards and Technology, Gaithersburg, Maryland 20899, United States

*Corresponds to: dhzhang@1su.edu and gjschneider@,1su.edu

ABSTRACT: Well-defined polypeptoids bearing oligomeric ethylene glycol side chains $\mathrm{PNMe}(\mathrm{OEt})_{\mathrm{n}} \mathrm{G}(\mathrm{n}=1-3)$ with controlled molecular weight $(3.26-28.6 \mathrm{~kg} / \mathrm{mol})$ and narrow molecular distribution (polydispersity index, PDI $=1.03-1.10$ ) have been synthesized by ringopening polymerization of the corresponding $N$-carboxyanhydrides having oligomeric ethylene glycol side chains $\left(\mathrm{Me}(\mathrm{OEt})_{\mathrm{n}}-\mathrm{NCA}, \mathrm{n}=1-3\right)$ using primary amine initiators. Kinetic studies of polymerization revealed a first-order dependence on the monomer concentration, consistent with a living polymerization. The obtained PEGylated polypeptoids are highly hydrophilic with good water solubility $(>200 \mathrm{mg} / \mathrm{mL})$ and are amorphous with the glass transition temperature $\left(\mathrm{T}_{\mathrm{g}}\right)$ in 41.1-46.4 ${ }^{\circ} \mathrm{C}$ range that increases with increasing molecular weight and decreasing side chain length. The DLS and SANS analysis revealed no appreciable adsorption of lysozyme to PNMeOEtG. PNMeOEtG having different molecular weight exhibited minimal cytotoxicity towards HEp2 cells. These combined results suggest the potential use of PEGylated polypeptoids as protein- resistant materials in the biomedical and biotechnological field. 
1

2

4 contact with human blood, including thrombosis, chronic inflammation and fast immunological

5 recognition. ${ }^{1-4}$ These biological responses may hinder the function of biomedical devices or

6 materials (e.g., the efficacy of drug delivery vehicles). ${ }^{1-4}$ Enhanced resistance to nonspecific

7 protein adsorption, therefore, is critical to the development of synthetic materials towards various

8 biomedical and biotechnological applications (e.g., tissue engineering, therapeutic delivery and

9 implant devices)

While the mechanisms of non-specific protein adsorption to surfaces are not fully understood, ${ }^{3}$ the balance of various non-covalent interactions (e.g., van der Waals, electrostatic and hydrophobic forces) between a protein and a surface is considered to be important. ${ }^{3}$ The water layer bound to hydrophilic polymer chains is often considered responsible for inhibiting protein adsorption. ${ }^{4-5}$ Based on the reported studies, protein-resistant materials usually share a set of molecular characteristics, the so-called "Whitesides rules": 1) hydrophilicity, 2) the presence of hydrogen bond acceptor groups, 3) the absence of hydrogen bond donor groups, and 4) the absence of net charge. ${ }^{4,6-7}$ The "Whitesides rules" have been widely applied for the rational design of protein-resistant materials. Many types of protein-resistant materials have been developed and characterized for their antifouling behaviors. This includes poly(ethylene glycol) (PEG), ${ }^{3,8}$ oligo/polypeptides, ${ }^{9-10}$ polycarbonates, ${ }^{11}$ polyoxazolines, ${ }^{12-14}$ polyacrylamides ${ }^{15-17}$ and zwitterionic polymers $^{3,18-19}$. Among them, PEG is considered as the gold standard of proteinresistant stealth polymers in polymer-based therapeutic delivery. The drug-PEG conjugates enhance the water solubility of drugs and decrease their interaction with blood components, 
1 leading to increased circulation half-life and decreased toxicity of drugs. However, PEG has

2 notable drawbacks including non-biodegradability, potential immunological recognition and

3 hypersensitivity provocation, as well as accumulation in tissue when the molecular weight of

4 PEG exceeds $40 \mathrm{KDa}^{3-4,8}$ Zwitterionic polymers (e.g., zwitterionic polycarbonates ${ }^{18}$ and

5 polybetaines ${ }^{3}$ ) which form a very stable hydration shell through strong ion-dipole interaction

6 with water are very promising protein-resistant materials. ${ }^{3-4}$ They are minimally soluble in most

7 common organic solvents, rendering the process of conjugating these polymers to hydrophobic

8 drugs more complex relative to that of non-ionic polymers. ${ }^{11}$ Polyoxazolines (e.g., poly(2-

9 methyl-2-oxazoline)), while exhibiting similar stealth behavior as PEG, is not backbone

10 degradable. The potential formation of poly (ethylene imine) from enzymatic degradation of the

11 amide bonds on the polyoxazolines side chain can lead to cytotoxicity. ${ }^{14,20-21}$ Polyacrylamides

12 are another category of protein-resistant polymers that is not backbone degradable. In addition,

13 the thermo-responsive characteristic of poly( $N$-isopropylacrylamide $)$ in particular enhances

14 protein adsorption at physiological temperature due to the increased dehydration and

15 hydrophobicity at higher temperature. ${ }^{15-16,22}$ While oliogomeric ${ }^{23-26}$ and polymeric peptides ${ }^{9,27-28}$

16 exhibiting stealth behavior are enzymatically degradable, their water solubility is $\mathrm{pH}$ dependent

17 (e.g., in the case of poly-L-lysine and poly-L-aspartate) and the circulation lifetime is reduced

18 when aggregation with oppositely charged biomolecules occurs. ${ }^{29-30}$ In addition, proteolysis of

19 peptides reduces their in vivo half-lives, limiting their use in long-term biological application

20 (e.g., long-term drug delivery). Polycarbonates have attracted considerable attention in the recent

21 years due to their low toxicity, potential cytocompatibility and biodegradability; ${ }^{31}$ however,

22 studies showed that polycarbonates are prone to fast degradation (within several days or weeks)

23 both hydrolytically ${ }^{32-33}$ and enzymatically ${ }^{34}$ and thus limit their long-term biological use. 
Poly ( $N$-substituted glycine) (a.k.a. polypeptoids), with an $N$-substituted polyglycine

2 backbone, are structural mimics of polypeptides. In contrast to polypeptides, which adopt

3 secondary structures (e.g., helix or sheet) stabilized by hydrogen bonding, polypeptoids lack

4 extensive hydrogen bonding and stereogenic centers on the backbone. These structural

5 characteristics render polypeptoids thermally processable, readily soluble in common organic

6 solvents, and more resistant towards enzymatic and hydrolytic degradation relative to

7 polypeptides. ${ }^{23-25,35-36}$ In addition, early studies showed that polypeptoids exhibit minimal

8 cytotoxicity, ${ }^{37-40}$ and are degradable under oxidative conditions that mimics tissue

9 inflammation. $^{40}$ The combination of these properties makes polypeptoids attractive for

10 biomedical and biotechnological applications. ${ }^{35,41-45}$ In recent years, oligo polypeptoids $\left(\mathrm{DP}_{\mathrm{n}} \leq\right.$

11 20) (e.g., polysarcocine, ${ }^{46} \operatorname{poly}(N$-methoxyethyl glycine $),{ }^{47-48} \operatorname{poly}(N$-hydroxyethyl glycine $\left.){ }^{48}\right)$

12 grafted onto $\mathrm{TiO}_{2}$ surface through a DOPA-Lys surface anchor have been shown to exhibit

13 excellent antifouling characteristics in inhibiting protein (e.g., human fibrinogen) adsorption and

14 cell (e.g., mammalian cell) attachment. The chain length of polypeptoids obtained by solid-phase

15 synthesis is limited to less than 50 mer. $^{43}$ Polysarcosine brushes obtained by surface-initiated

16 ring-opening polymerization (SI-ROP) of sarcosine-derived $N$-carboxyanhyride (Me-NCA) also

17 exhibited antifouling properties. ${ }^{49}$ Early studies of antifouling polypeptoids have all been focused

18 on polypeptoids anchored on various surfaces. There is no study on the interaction of soluble

19 polypeptoids with protein in solution.

20 In this contribution, we report the design and synthesis of a series of structurally well-

21 defined polypeptoids bearing oligomeric ethylene glycol side chains by primary amine-initiated

22 ring-opening polymerization of the corresponding $N$-substituted $N$-carboxyanhydrides (Scheme

23 2). These PEGylated polypeptoids are highly water soluble, charge neutral and have hydrogen 
1 bond accepting groups both on the backbones and side chains, which fulfill all the criteria of the

2 abovementioned "Whitesides rule" for protein-resistant materials. The CellTiter-Blue cell

3 viability assays revealed these PEGylated polypeptoids are minimally cytotoxic towards HEp2

4 cells. The small-angle neutron scattering (SANS) and dynamic light scattering (DLS) analysis

5 revealed the absence of obvious adsorption of lysozyme to PNMeOEtG in aqueous solution.

6 These results suggested the potential use of PEGylated polypeptoids as protein-resistant

7 materials for biological applications.

8 EXPERIMENTAL SECTION

9 General considerations. All chemicals were purchased from Sigma Aldrich and used as 10 received unless otherwise noted. The primary amine (2-(2-methoxyethoxy)ethanamine (4) and 211 (2-(2-methoxyethoxy)ethoxy)ethylamine) (8) were synthesized in good yields (61.3-67.2\%, 12 Figure S7 and S16) by adapting a reported procedue. ${ }^{50}$ All the solvents used in monomer 13 preparation and polymerization were purified by passing through alumina columns under argon. 14 Toluene- $\mathrm{d}_{8}$ was purified by vacuum transfer after stirring over $\mathrm{CaH}_{2}$ overnight. ${ }^{1} \mathrm{H}$ and ${ }^{13} \mathrm{C}\left\{{ }^{1} \mathrm{H}\right\}$ 15 NMR spectra were obtained using a Bruker AV-400 Nanobay spectrometer (400 MHz for ${ }^{1} \mathrm{H}$ 16 NMR and $100 \mathrm{MHz}$ for $\left.{ }^{13} \mathrm{C}\left\{{ }^{1} \mathrm{H}\right\} \mathrm{NMR}\right)$ and a Bruker AV-500 spectrometer (500 MHz for ${ }^{1} \mathrm{H}$ 17 NMR and $125 \mathrm{MHz}$ for $\left.{ }^{13} \mathrm{C}\left\{{ }^{1} \mathrm{H}\right\} \mathrm{NMR}\right)$ at $298 \mathrm{~K}$. Chemical shifts $(\delta)$ given in parts per million 18 (ppm) were referenced to protio impurities or the ${ }^{13} \mathrm{C}$ isotopes of deuterated solvents $\left(\mathrm{CDCl}_{3}\right.$ and $19 \mathrm{D}_{2} \mathrm{O}$ ). High resolution mass spectroscopy (HRMS) spectra were obtained using 6210 ESI-TOF 20 mass spectrometer (Aglient Technologies). The HEPES buffer $(0.1 \mathrm{~mol} / \mathrm{L})$ used for sample 21 preparation in SANS study was prepared by dissolving a known amount of pure HEPES (2.38 g) 22 powders in $\mathrm{D}_{2} \mathrm{O}(80 \mathrm{~mL})$ and sodium hydroxide $(\mathrm{NaOH})$ and hydrochloric acid $(\mathrm{HCl})$ were used 23 to adjust the $\mathrm{pH}$ of the buffer. 
Size-exclusion chromatography (SEC) analysis. SEC analysis of the polypeptoids were

2 performed using an Agilent 1200 system (Agilent 1200 series degasser, isocratic pump, auto

3 sampler and column heater) equipped with three Phenomenex $5 \mu \mathrm{m}, 300 \times 7.8 \mathrm{~mm}$ columns, a

4 Wyatt OptilabrEX differential refractive index (DRI) detector with a $690 \mathrm{~nm}$ light source, and a

5 Wyatt DAWN EOS multiangle light scattering (MALS) detector (GaAs $30 \mathrm{~mW}$ laser at $\lambda=690$

$6 \mathrm{~nm})$. DMF with $0.1 \mathrm{M} \mathrm{LiBr}$ was used as the eluent at a flow rate of $0.5 \mathrm{~mL} \cdot \mathrm{min}^{-1}$. The column

7 and detector temperature was set at $25{ }^{\circ} \mathrm{C}$. All data analysis was performed using Wyatt Astra V

85.3 software. Polymer molecular weight $\left(M_{\mathrm{n}}\right)$ and molecular weight distribution (PDI) were

9 obtained by the Zimm model fit of the MALS-DRI data. The absolute polymer molecular weight

$10\left(M_{\mathrm{n}}\right)$ was determined using the measured refractive index increment $\mathrm{d} n / \mathrm{d} c$ values. The refractive

11 index increment $(\mathrm{d} n / \mathrm{d} c)$ of the polymer was determined using Wyatt OptilabrEX DRI detector

12 and Astra software $\mathrm{d} n / \mathrm{d} c$ template. The polymer was dissolved in DMF with $0.1 \mathrm{~mol} / \mathrm{L} \mathrm{LiBr}$ to

13 prepare six dilute solutions with known concentrations $(0.05-3.00 \mathrm{mg} / \mathrm{mL})$ using volumetric

14 flasks. The solutions were injected to the DRI detector and the corresponding $\mathrm{d} n / \mathrm{d} c$ values were

15 determined from the linear fit of the respective refractive index versus polymer concentration

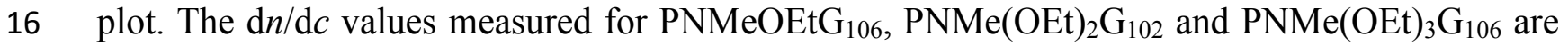
$17 \quad 0.0633(4), 0.0686(8)$ and $0.0563(6) \mathrm{mL} / \mathrm{g}$, respectively. spectrometry analysis. The MALDI-TOF MS experiments were conducted on a Bruker 20 ultrafleXtreme tandem time-of-flight (TOF) mass spectrometer equipped with a smartbeam-II ${ }^{\mathrm{TM}}$ $211000 \mathrm{~Hz}$ laser (Bruker Daltonics, Billerica, MA). The instrument was calibrated with Peptide 22 Calibration Standard II (Bruker Daltonics, Billerica, MA). A saturated solution of $\alpha$-cyano-423 hydroxycinnamic acid (CHCA) in methanol was used as the matrix in all measurements. The 
1 polymer samples $(10 \mathrm{mg} / \mathrm{mL}$ in THF) were mixed with the saturated matrix solutions at 1:1

2 volume ratio and vortexed thoroughly. The mixtures $(1 \mu \mathrm{L})$ were deposited onto a 384 -well

3 ground-steel sample plate and were allowed to be fully dried prior to measurement using positive

4 reflector mode. Data analysis was carried out using flexAnalysis software.

5 Thermogravimetric analysis (TGA). TGA analysis of the polypeptoid solid samples

6 was conducted on a TA TGA 2950 under nitrogen at the heating rate of $10{ }^{\circ} \mathrm{C} \cdot \mathrm{min}^{-1}$. The

7 decomposition temperature $\left(T_{d}\right)$ of the polypeptoids was determined by the temperature of the

8 maximum weight loss rate.

9 Differential scanning calorimetry (DSC) analysis. DSC analysis of the polypeptoid 10 solid samples was conducted on a TA DSC 2920 calorimeter under nitrogen. The polymer $(\sim 5$ $11 \mathrm{mg}$ ) was sealed into the hermetic aluminum pan and an empty hermetic aluminum pan was used 12 as the reference. The sample containing pans were first heated from $-50{ }^{\circ} \mathrm{C}$ to $200{ }^{\circ} \mathrm{C}$ at 10 $13{ }^{\circ} \mathrm{C} / \mathrm{min}$, cooled to $-50{ }^{\circ} \mathrm{C}$ at $10{ }^{\circ} \mathrm{C} / \mathrm{min}$ and remained at $-50{ }^{\circ} \mathrm{C}$ for $5 \mathrm{~min}$ and reheated to $200{ }^{\circ} \mathrm{C}$ at $1410{ }^{\circ} \mathrm{C} / \mathrm{min}$. The glass transition temperature $\left(\mathrm{T}_{\mathrm{g}}\right)$ was determined as the temperature 15 corresponding to the minimum of the derivative of the heat flow trace around the glass transition. 16 Dynamic light scattering (DLS) analysis. PNMeOEtG1 $1_{06}$, PEG8000 or lysozyme was 17 dissolved in PBS at $1 \mathrm{wt} \%$ and filtered through $0.22 \mu \mathrm{m}$ filters before measurements. All the 18 samples were measured using Malvern Zetasizer Nano-zs (Zen3600). The He-Ne laser operating 19 at $\lambda=633 \mathrm{~nm}$ was utilized, and scattered light intensity was detected at an external angle of 173 $20{ }^{\circ} \mathrm{C}$ using non-invasive backscatter (NIBS) technology. Data from three measurements with 12 21 scans for each measurement was recorded. The hydrodynamic diameters and PDI of the samples 22 were obtained from cumulant analysis. ${ }^{51}$ 
Small-angle neutron scattering (SANS) analysis. The SANS studies were performed at

2 the NIST Center for Neutron Research (NCNR) in Gaithersburg, MD, on the NG7 30 m SANS

3 instrument, using neutrons with wavelength $\lambda=6 \AA$ and wavelength spread, $\Delta \lambda / \lambda=11 \%$. The

4 temperature was maintained at $20 \pm 0.1{ }^{\circ} \mathrm{C}$ using a circulating bath. A typical SANS data

5 reduction protocol, which consisted of subtracting scattering contributions from the empty cell (2

$6 \mathrm{~mm}$ demountable titanium cells), background scattering, and sorting data collected from two

7 different detector distances was used to yield normalized scattering intensities, $\mathrm{I}(\mathrm{Q})\left(\mathrm{cm}^{-1}\right) a . k . a$.

8 the macroscopic scattering cross-section $(d \Sigma / d \Omega)$ as a function of the scattering vector, $\mathrm{Q}\left(\AA^{-1}\right)$.

9 Data reduction was conducted employing the NCNR Igor-pro platform. The SANS scattering 10 intensity for our macromolecular solution is modelled as ${ }^{52}$

$$
\frac{d \Sigma}{d \Omega}=\phi \Delta \rho^{2} V P(Q) S(Q)
$$

11 Here, $\phi$ is the volume fraction of the molecules, $\Delta \rho$ and $\mathrm{V}$, are their average scattering contrast

12 and volume, respectively. The single molecular form factor, $P(Q)$, averaged particle scattering

13 over the ensemble of sizes and orientations, is related to the particle structure. The effective

14 structure factor, $S(Q)$, provides information about the intermolecular interaction. For dilute

15 solutions of non-interacting molecules, $S(Q) \approx 1$. In the current work we have modelled the

16 form factor and the structure for lysozyme molecule using a hard sphere approximation. ${ }^{53-54}$ The

17 form factor for the polymer is modelled using the random Gaussian coil. ${ }^{55}$

(1), ethyl 2-((2-(2- 
1 (14.7 $\mathrm{mL}, 0.13 \mathrm{~mol})$ dissolved in ethyl acetate $(50 \mathrm{~mL})$ was added dropwise to the above mixture

2 at room temperature and stirred at room temperature for $4 \mathrm{~h}$. The white precipitation was

3 removed by filtration and the filtrate was condensed to obtain the crude product as pale yellow

4 liquid (21.2 g). The crude product was purified by column chromatography performed on silica

5 gel (230-400 mesh, $60 \AA$, Sorbent Technologies) using ethyl acetate/methanol $\left(\mathrm{R}_{\mathrm{f}}=0.5\right.$ in $5 \%$

$6 \mathrm{MeOH})$ as the eluent to afford the desired product as colorless liquid (17.2 g, 82.3\% yield). ${ }^{1} \mathrm{H}$

$7 \operatorname{NMR}\left(\delta\right.$ in $\left.\mathrm{CDCl}_{3}, 400 \mathrm{MHz}, \mathrm{ppm}\right): 1.23-1.26 \mathrm{ppm}\left(\mathrm{t}, \mathrm{J}=7.16 \mathrm{~Hz}, 3 \mathrm{H},-\mathrm{COOCH}_{2} \mathrm{CH}_{3}\right) ; 1.87$

8 ppm (s, $1 \mathrm{H},-\mathrm{NH}$ ); 2.76-2.79 ppm (t, $\left.\mathrm{J}=5.12 \mathrm{~Hz}, 2 \mathrm{H},-\mathrm{CH}_{2} \mathrm{NHCH}_{2} \mathrm{CH}_{2}-\right) ; 3.33$ ppm (s, $3 \mathrm{H},-$

$\left.9 \mathrm{OCH}_{3}\right) ; 3.40 \mathrm{ppm}\left(\mathrm{s}, 2 \mathrm{H},-\mathrm{NHCH}_{2} \mathrm{COO}-\right) ; 3.45-3.48 \mathrm{ppm}\left(\mathrm{t}, \mathrm{J}=5.08,2 \mathrm{H}, \mathrm{CH}_{3} \mathrm{OCH}_{2} \mathrm{CH}_{2}-\right)$; 4.14-

$104.19 \mathrm{ppm}\left(\mathrm{q}, \mathrm{J}=7.12 \mathrm{~Hz}, 2 \mathrm{H},-\mathrm{COOCH}_{2} \mathrm{CH}_{3}\right) \cdot{ }^{13} \mathrm{C}\left\{{ }^{1} \mathrm{H}\right\}$ NMR ( $\delta$ in $\left.\mathrm{CDCl}_{3}, 125 \mathrm{MHz}, \mathrm{ppm}\right): 14.2$

11 ppm $\left(-\mathrm{COOCH}_{2} \mathrm{CH}_{3}\right) ; 48.8$ ppm $\left(-\mathrm{CH}_{2} \mathrm{NHCH}_{2} \mathrm{CH}_{2}-\right) ; 51.0$ ppm $\left(-\mathrm{OCH}_{3}\right) ; 58.7$ ppm (-

$\left.12 \mathrm{NHCH}_{2} \mathrm{COO}-\right) ; 60.7$ ppm $\left(\mathrm{CH}_{3} \mathrm{OCH}_{2} \mathrm{CH}_{2}-\right) ; 72.1$ ppm $\left(-\mathrm{COOCH}_{2} \mathrm{CH}_{3}\right) ; 172.3$ ppm (-

$\left.13 \mathrm{CH}_{2} \mathrm{COOH}\right)$. Ethyl 2-((2-(2-methoxyethoxy)ethyl)amino)acetate (5) in 68.5-70.5\% yield was

14 synthesized by the same procedure as that for the compound 1. ${ }^{1} \mathrm{H} \mathrm{NMR}\left(\delta\right.$ in $\mathrm{CDCl}_{3}, 400 \mathrm{MHz}$,

15 ppm): 4.18-4.24 ppm (q, J $\left.=7.12 \mathrm{~Hz}, 2 \mathrm{H},-\mathrm{COOCH}_{2} \mathrm{CH}_{3}\right) ; 3.56-3.65 \mathrm{ppm}(\mathrm{m}, 6 \mathrm{H}$, $16 \mathrm{CH}_{3} \mathrm{OCH}_{2} \mathrm{CH}_{2} \mathrm{OCH}_{2}$ ) $; 3.45$ ppm (s, $\left.2 \mathrm{H},-\mathrm{NHCH}_{2} \mathrm{COO}-\right) ; 3.41 \mathrm{ppm}\left(\mathrm{s}, 3 \mathrm{H}, \mathrm{CH}_{3} \mathrm{O}-\right) ; 2.83-2.86$

$17 \operatorname{ppm}\left(\mathrm{t}, \mathrm{J}=10.6 \mathrm{~Hz}, 2 \mathrm{H},-\mathrm{CH}_{2} \mathrm{NHCH}_{2}\right.$ ) $; 1.83 \mathrm{ppm}(\mathrm{s},-\mathrm{NH}-) ; 1.28-1.31 \mathrm{ppm}(\mathrm{t}, \mathrm{J}=14.3 \mathrm{~Hz}, 3 \mathrm{H}$, $\left.18-\mathrm{CH}_{2} \mathrm{CH}_{3}\right) \cdot{ }^{13} \mathrm{C}\left\{{ }^{1} \mathrm{H}\right\}$ NMR ( $\delta$ in $\left.\mathrm{CDCl}_{3}, 125 \mathrm{MHz}, \mathrm{ppm}\right): 172.3 \mathrm{ppm}\left(-\mathrm{COOCH}_{2} \mathrm{CH}_{3}\right) ; 70.3-71.9$ 19 ppm $\left(\mathrm{CH}_{3} \mathrm{OCH}_{2} \mathrm{CH}_{2} \mathrm{OCH}_{2}-\right) ; \quad$ 59.0-60.7 ppm $\quad\left(-\mathrm{CH}_{2} \mathrm{COOCH}_{2}\right) ; \quad 48.8-51.0 \quad$ ppm $20 \quad\left(\mathrm{CH}_{3} \mathrm{OCH}_{2} \mathrm{CH}_{2} \mathrm{OCH}_{2} \mathrm{CH}_{2} \mathrm{NH}-\right) ; \quad 14.2 \quad$ ppm $\quad\left(-\mathrm{COOCH}_{2} \mathrm{CH}_{3}\right)$. Ethyl 2-((2-(2-(221 ethoxyethoxy)ethyl)amino)acetate (9) in 66.9-71.6\% yield was synthesized by the same 22 procedure as that for compound 1 and 5. ${ }^{1} \mathrm{H} \mathrm{NMR}$ ( $\delta$ in $\mathrm{CDCl}_{3}, 400 \mathrm{MHz}, \mathrm{ppm}$ ): 4.16-4.21 ppm $23\left(\mathrm{q}, \mathrm{J}=7.12 \mathrm{~Hz}, 2 \mathrm{H}, \mathrm{CH}_{3} \mathrm{CH}_{2} \mathrm{COO}-\right)$; 3.54-3.66 ppm (m, $\left.10 \mathrm{H},-\mathrm{CH}_{2} \mathrm{OCH}_{2} \mathrm{CH}_{2} \mathrm{OCH}_{2} \mathrm{CH}_{2} \mathrm{OCH}_{3}\right)$; 
$13.44 \mathrm{ppm}\left(\mathrm{s}, 2 \mathrm{H},-\mathrm{NHCH}_{2} \mathrm{COO}-\right) ; 3.38 \mathrm{ppm}\left(\mathrm{s}, 3 \mathrm{H},-\mathrm{OCH}_{3}\right) ; 2.80-2.83$ ppm (t, 2H, -

$\left.2 \mathrm{CH}_{2} \mathrm{NHCH}_{2} \mathrm{COO}-\right) ; 2.09$ ppm (bs, $\left.1 \mathrm{H},-\mathrm{N} H-\right) ; 1.26-.1 .29 \mathrm{ppm}\left(\mathrm{t}, 3 \mathrm{H},-\mathrm{COOCH}_{2} \mathrm{CH}_{3}\right) .{ }^{13} \mathrm{C}\left\{{ }^{1} \mathrm{H}\right\}$

$3 \mathrm{NMR}\left(\delta\right.$ in $\left.\mathrm{CDCl}_{3}, 125 \mathrm{MHz}, \quad \mathrm{ppm}\right)$ : 172.2 ppm (-COO-); 70.3-71.9 ppm (-

$\left.4 \mathrm{CH}_{2} \mathrm{CH}_{2} \mathrm{OCH}_{2} \mathrm{CH}_{2} \mathrm{OCH}_{2} \mathrm{CH}_{2} \mathrm{NHCH}_{2} \mathrm{COOCH}_{2}-\right)$; 59.0-60.7 ppm $\left(-\mathrm{CH}_{2} \mathrm{CH}_{2} \mathrm{NHCH}_{2}-\right)$; 48.8-50.9

$5 \operatorname{ppm}\left(\mathrm{CH}_{3} \mathrm{OCH}_{2} \mathrm{CH}_{2} \mathrm{OCH}_{2} \mathrm{CH}_{2} \mathrm{OCH}_{2} \mathrm{CH}_{2}-\right) ; 14.2 \mathrm{ppm}\left(-\mathrm{COOCH}_{2} \mathrm{CH}_{3}\right)$.

6 Synthesis of ethyl 2-((2-methoxyethyl)amino)acetic acid hydrochloride (2), ethyl 2-

7 ((2-(2-methoxyethoxy)ethyl)amino)acetate hydrochloride (6) and ethyl 2-((2-(2-(2-

8 ethoxyethoxy)ethyl)amino)acetate hydrochloride (10). Compound 1 (16.5 g, $0.10 \mathrm{~mol})$ was

9 added into an aqueous $\mathrm{HCl}(104 \mathrm{~mL}, 4 \mathrm{~mol} / \mathrm{L})$ and heated at $80{ }^{\circ} \mathrm{C}$ for $24 \mathrm{~h}$. The water was

10 removed by rotary evaporation to obtain a colorless oil (12.8 g, 100\% yield), which was used

11 directly in the synthesis of compound 3 without further purification. ${ }^{1} \mathrm{H}$ NMR $\left(\delta\right.$ in $\mathrm{D}_{2} \mathrm{O}, 400$

$12 \mathrm{MHz}, \mathrm{ppm})$ : 3.25-3.27 ppm (t, $\left.\mathrm{J}=4.00 \mathrm{~Hz}, 2 \mathrm{H},-\mathrm{CH}_{2} \mathrm{NHCH}_{2} \mathrm{CH}_{2}-\right) ; 3.30 \mathrm{ppm}\left(\mathrm{s}, 3 \mathrm{H},-\mathrm{OCH}_{3}\right)$;

13 3.64-3.66 ppm (t, J = 4.00 Hz, 2H, $\mathrm{CH}_{3} \mathrm{OCH}_{2} \mathrm{CH}_{2}$ ); $3.91 \mathrm{ppm}\left(\mathrm{s}, 2 \mathrm{H},-\mathrm{NHCH} \mathrm{COO}_{-}\right) .{ }^{13} \mathrm{C}\left\{{ }^{1} \mathrm{H}\right\}$

$14 \mathrm{NMR}\left(\delta\right.$ in $\left.\mathrm{D}_{2} \mathrm{O}, 125 \mathrm{MHz}, \mathrm{ppm}\right): 46.7 \mathrm{ppm}\left(-\mathrm{CH}_{2} \mathrm{NHCH}_{2} \mathrm{CH}_{2}-\right) ; 47.2 \mathrm{ppm}\left(-\mathrm{OCH}_{3}\right) ; 58.3 \mathrm{ppm}$

$15\left(\mathrm{CH}_{3} \mathrm{OCH}_{2} \mathrm{CH}_{2}-\right) ; 66.7$ ppm (-NHCH$\left.{ }_{2} \mathrm{COO}-\right) ; 168.8$ ppm $\left(-\mathrm{CH}_{2} \mathrm{COOH}\right)$. Ethyl 2-((2-(2-

16 methoxyethoxy)ethyl)amino)acetate hydrochloride (6) in $\sim 100 \%$ yield was synthesized by the

17 same procedure as that for $2 .{ }^{1} \mathrm{H}$ NMR $\left(\delta\right.$ in $\left.\mathrm{D}_{2} \mathrm{O}, 400 \mathrm{MHz}, \mathrm{ppm}\right): 3.91 \mathrm{ppm}(\mathrm{s}, 2 \mathrm{H}$, -

$\left.18 \mathrm{NHCH}_{2} \mathrm{COOH}\right) ; 3.55-3.74$ ppm (m, 6H, $\left.\mathrm{CH}_{3} \mathrm{OCH}_{2} \mathrm{CH}_{2} \mathrm{OCH}_{2}-\right) ; 3.31$ ppm (s, 3H, CH $\mathrm{H}_{3} \mathrm{O}-$; 3.27-

$193.29 \mathrm{ppm}(\mathrm{t}, \mathrm{J}=9.96 \mathrm{~Hz},-\mathrm{CH} 2 \mathrm{CH}-) .{ }^{13} \mathrm{C}\left\{{ }^{1} \mathrm{H}\right\}$ NMR $\left(\delta\right.$ in $\left.\mathrm{D}_{2} \mathrm{O}, 125 \mathrm{MHz}, \mathrm{ppm}\right): 169.0$ ppm (-

$20 \mathrm{COOH}) ; 65.3-71.0$ ppm $\left(\mathrm{CH}_{3} \mathrm{OCH}_{2} \mathrm{CH}_{2} \mathrm{OCH}_{2} \mathrm{CH}_{2} \mathrm{NHCH}_{2}-\right)$; 58.0 ppm $\left(-\mathrm{CH}_{2} \mathrm{CH}_{2} \mathrm{NH}-\right)$; 46.9-

2147.3 ppm $\left(\mathrm{CH}_{3} \mathrm{OCH}_{2} \mathrm{CH}_{2} \mathrm{OCH}_{2} \mathrm{CH}_{2}-\right)$. Ethyl 2-((2-(2-(2-ethoxyethoxy)ethyl)amino)acetate

22 hydrochloride (10) in $\sim 100 \%$ yield was synthesized by the same procedure as that for compound

232 and 6. ${ }^{1} \mathrm{H}$ NMR $\left(\delta\right.$ in $\mathrm{D}_{2} \mathrm{O}, \quad 400$ MHz, ppm): 3.28-3.29 ppm (m, 5H, 
$\left.2 \mathrm{CH}_{3} \mathrm{OCH}_{2} \mathrm{CH}_{2} \mathrm{OCH}_{2} \mathrm{CH}_{2} \mathrm{OCH}_{2} \mathrm{CH}_{2}-\right) ; 3.61-3.65$ ppm (m, 6H, $\mathrm{CH}_{3} \mathrm{OCH}_{2} \mathrm{CH}_{2} \mathrm{OCH}_{2} \mathrm{CH}_{2-}$ ); 3.74-

$3 \quad 3.75$ ppm (m, 2H, $\left.\mathrm{CH}_{3} \mathrm{OCH}_{2^{-}}\right) ; 3.92 \mathrm{ppm}\left(\mathrm{s}, 2 \mathrm{H}, \mathrm{HOOCCH} 2^{-}\right) .{ }^{13} \mathrm{C}\left\{{ }^{1} \mathrm{H}\right\} \mathrm{NMR}\left(\delta\right.$ in $\mathrm{D}_{2} \mathrm{O}, 125$

$4 \mathrm{MHz}, \quad$ ppm): $\quad 46.9-47.2 \quad$ ppm $\quad\left(\mathrm{CH}_{3} \mathrm{OCH}_{2} \mathrm{CH}_{2} \mathrm{OCH}_{2} \mathrm{CH}_{2} \mathrm{OCH}_{2} \mathrm{CH}_{2}-\right) ; \quad 58.0 \quad$ ppm

$5 \quad\left(\mathrm{CH}_{3} \mathrm{OCH}_{2} \mathrm{CH}_{2} \mathrm{OCH}_{2} \mathrm{CH}_{2} \mathrm{OCH}_{2} \mathrm{CH}_{2}-\right) ; 65.2 \mathrm{ppm}\left(\mathrm{CH}_{3} \mathrm{OCH}_{2} \mathrm{CH}_{2} \mathrm{OCH}_{2} \mathrm{CH}_{2}-\right)$; 69.4-69.5 ppm

$6\left(\mathrm{CH}_{3} \mathrm{OCH}_{2} \mathrm{CH}_{2} \mathrm{OCH}_{2} \mathrm{CH}_{2}-\right) ; 0.9$ ppm $\left(\mathrm{HOOCCH}_{2}-\right) ; 168.9 \mathrm{ppm}\left(\mathrm{HOOCCH}_{2^{-}}\right)$.

Synthesis of 2-(N, N-tert-butoxycarbonyl-2-methoxyethyl)amino)acetic acid (3), 2-(N,

$8 \quad \mathrm{~N}$-tert-butoxycarbonyl-2-(2-methoxyethoxyethyl)amino)acetic acid (7) and $2-(\mathrm{N}, \mathrm{N}$-tert-

9 butoxycarbonyl-2-(2-(2-(2-ethoxyethoxy)ethyl)amino) acetic acid (11). Compound 2 (16.0 g,

$100.09 \mathrm{~mol})$, triethylamine $(62.7 \mathrm{~mL}, 0.45 \mathrm{~mol})$ and di-tert-butyl dicarbonate $(49 \mathrm{~g}, 0.23 \mathrm{~mol})$ were

11 mixed in distilled water $(200 \mathrm{~mL})$ and stirred at $25{ }^{\circ} \mathrm{C}$ for $24 \mathrm{~h}$. The reaction mixture was

12 extracted with hexanes $(2 \times 200 \mathrm{~mL})$ to remove extra di-tert-butyl dicarbonate. The aqueous

13 phase was acidified with aqueous $\mathrm{HCl}(4 \mathrm{~mol} / \mathrm{L})$ at $0{ }^{\circ} \mathrm{C}$ and extracted with ethyl acetate $(3 \times 100$

$14 \mathrm{~mL})$. The organic phase was washed with brine $(1 \times 200 \mathrm{~mL})$ followed by drying over anhydrous

$15 \mathrm{MgSO}_{4}$. After filtration, the solvent was removed to obtain the desired product as white solid

$16 \quad$ (18.5 g, 88.2\%). ${ }^{1} \mathrm{H}$ NMR ( $\delta$ in $\left.\mathrm{CDCl}_{3}, 400 \mathrm{MHz}, \mathrm{ppm}\right): 1.45-1.49 \mathrm{ppm}\left(\mathrm{d}, 9 \mathrm{H},-\mathrm{C}(\mathrm{CH})_{3}\right) ; 3.35-$

173.38 ppm (d, 3H, $\left.-\mathrm{OCH}_{3}\right) ; 3.47-3.53\left(\mathrm{~m}, 2 \mathrm{H}, \mathrm{CH}_{3} \mathrm{OCH}_{2} \mathrm{CH}_{2}-\right) ; 3.59-3.61$ ppm (m, 2H,

$\left.18 \mathrm{CH}_{3} \mathrm{OCH}_{2} \mathrm{CH}_{2-}\right) ; 4.01-4.09$ (d, 2H, HOOCCH2-). ${ }^{13} \mathrm{C}\left\{{ }^{1} \mathrm{H}\right\} \mathrm{NMR}\left(\delta\right.$ in $\left.\mathrm{CDCl}_{3}, 125 \mathrm{MHz}, \mathrm{ppm}\right)$ :

19 28.2-28.3 ppm $\left(-\mathrm{C}\left(\mathrm{CH}_{3}\right)_{3}\right) ; 48.5-48.7 \mathrm{ppm}\left(\mathrm{CH}_{3} \mathrm{OCH}_{2} \mathrm{CH}_{2^{-}}\right) ;$50.3-51.6 ppm $\left(\mathrm{CH}_{3} \mathrm{OCH}_{2} \mathrm{CH}_{2}-\right)$;

20 58.7-57.4 ppm $\left(\mathrm{CH}_{3} \mathrm{OCH}_{2} \mathrm{CH}_{2}-\right)$; 71.5-71.6 ppm $\left(\mathrm{HOOCCH}_{2}-\right) ; 80.9-81.0$ ppm $\left(-\mathrm{C}\left(\mathrm{CH}_{3}\right)_{3}\right)$;

$21 \quad$ 155.0-155.8 ppm (-COOC $\left.\left(\mathrm{CH}_{3}\right)_{3}\right) ; 174.2-174.5$ ppm $\left(-\mathrm{CH}_{2} \mathrm{COOH}\right) .2-(N, N$-tert-butoxycarbonyl-

22 2-(2-methoxyethoxyethyl)amino)acetic acid (7) in 80.5-82.9\% yield was synthesized by the same

23 procedure as that for compound 3. ${ }^{1} \mathrm{H} \mathrm{NMR}\left(\delta\right.$ in $\left.\mathrm{CDCl}_{3}, 400 \mathrm{MHz}, \mathrm{ppm}\right): 4.03-4.11 \mathrm{ppm}(\mathrm{d}, 2 \mathrm{H}$, 
$\left.1 \mathrm{HOOCCH}_{2}-\right)$; 3.48-3.69 ppm (m, 8H, - $\left.\mathrm{CH}_{2} \mathrm{CH}_{2} \mathrm{OCH}_{2} \mathrm{CH}_{2} \mathrm{OCH}_{3}\right) ; 3.39$ ppm (s, $3 \mathrm{H},-\mathrm{OCH}_{3}$ );

2 1.45-1.48 ppm (d, 9H, $\left.-\mathrm{C}\left(\mathrm{CH}_{3}\right)_{3}\right) .{ }^{13} \mathrm{C}\left\{{ }^{1} \mathrm{H}\right\} \mathrm{NMR}\left(\delta\right.$ in $\left.\mathrm{CDCl}_{3}, 125 \mathrm{MHz}, \mathrm{ppm}\right): 28.2-28.4 \mathrm{ppm}(-$

$\left.3 \mathrm{C}\left(\mathrm{CH}_{3}\right)_{3}\right)$; 48.4-50.1 ppm $\left(\mathrm{CH}_{3} \mathrm{OCH}_{2} \mathrm{CH}_{2} \mathrm{OCH}_{2} \mathrm{CH}_{2}-\right)$; 58.7-58.8 ppm $\left(\mathrm{CH}_{3} \mathrm{OCH}_{2} \mathrm{CH}_{2} \mathrm{OCH}_{2} \mathrm{CH}_{2}-\right.$

4 ); 69.9-70.5 ppm $\left(\mathrm{CH}_{3} \mathrm{OCH}_{2} \mathrm{CH}_{2}-\right)$; 71.9-72.0 ppm $\left(\mathrm{HOOCCH}_{2}-\right)$; 80.5-80.6 ppm $\left(-\mathrm{C}\left(\mathrm{CH}_{3}\right)_{3}\right)$;

$5 \quad$ 155.3-155.7 ppm (-COOC $\left.\left(\mathrm{CH}_{3}\right)_{3}\right) ; 172.6-172.7 \mathrm{ppm}\left(-\mathrm{CH}_{2} \mathrm{COOH}\right) .2-(N$, N-tert-butoxycarbonyl-

6 2-(2-(2-(2-ethoxyethoxy)ethyl)amino) acetic acid (11) in 80.1-84.3\% yield was synthesized by

7 the same procedure as that for compound 3 and $7 .{ }^{1} \mathrm{H}$ NMR ( $\delta$ in $\left.\mathrm{CDCl}_{3}, 400 \mathrm{MHz}, \mathrm{ppm}\right): 4.00-$

$84.08 \mathrm{ppm}\left(\mathrm{d}, 2 \mathrm{H}, \mathrm{HOOCCH}_{2}-\right)$; 3.47-3.64 ppm (m, $12 \mathrm{H},-\mathrm{CH}_{2} \mathrm{CH}_{2} \mathrm{OCH}_{2} \mathrm{CH}_{2} \mathrm{OCH}_{2} \mathrm{CH}_{2}$ ); 3.39-

$9 \quad 3.41 \mathrm{ppm}\left(\mathrm{m}, 3 \mathrm{H},-\mathrm{OCH} H_{3}\right) ; 1.44-1.47 \mathrm{ppm}\left(\mathrm{d}, 9 \mathrm{H},-\mathrm{C}\left(\mathrm{CH}_{3}\right)_{3}\right) .{ }^{13} \mathrm{C}\left\{{ }^{1} \mathrm{H}\right\}$ NMR $\left(\delta\right.$ in $\mathrm{CDCl}_{3}, 125$

$10 \mathrm{MHz}, \mathrm{ppm})$ : 28.2-28.3 ppm (-C(CH$\left.)_{3}\right)$; 48.5-51.3 ppm $\left(\mathrm{CH}_{3} \mathrm{OCH}_{2} \mathrm{CH}_{2} \mathrm{OCH}_{2} \mathrm{CH}_{2} \mathrm{OCH}_{2} \mathrm{CH}_{2}-\right)$;

11 58.9-59.0 ppm $\left(\mathrm{CH}_{3} \mathrm{OCH}_{2} \mathrm{CH}_{2} \mathrm{OCH}_{2} \mathrm{CH}_{2}-\right) ; 70.1-70.4$ ppm $\left(\mathrm{CH}_{3} \mathrm{OCH}_{2} \mathrm{CH}_{2} \mathrm{OCH}_{2} \mathrm{CH}_{2}-\right)$; 71.6-

1271.8 ppm $\left(\mathrm{HOOCCH}_{2}-\right) ; 80.7-80.8$ ppm $\left(-\mathrm{C}\left(\mathrm{CH}_{3}\right)_{3}\right) ; 155.1-155.8$ ppm $\left(-\mathrm{COOC}\left(\mathrm{CH}_{3}\right)_{3}\right) ; 173.9$ $13 \operatorname{ppm}\left(-\mathrm{CH}_{2} \mathrm{COOH}\right)$.

Synthesis of MeOEt-NCA $\left(M_{1}\right), \operatorname{Me}(\mathrm{OEt})_{2}$-NCA $\left(M_{2}\right)$ and $\operatorname{Me}(\mathrm{OEt})_{3}$-NCA $\left(\mathrm{M}_{3}\right)$.

Compound 3 (10.5 g, $0.045 \mathrm{~mol})$ was dissolved in anhydrous dichloromethane (150 mL) under a nitrogen atmosphere. $\mathrm{PCl}_{3}(3.1 \mathrm{~mL}, 0.036 \mathrm{~mol})$ was added dropwise to the solution at $0{ }^{\circ} \mathrm{C}$ and

17 the mixture was stirred at $25{ }^{\circ} \mathrm{C}$ for $2 \mathrm{~h}$. The solvent was removed under vacuum to obtain 18 yellowish viscous residue. In the glovebox, the residue was extracted with anhydrous 19 dichoromethane $(3 \times 20 \mathrm{~mL})$ and filtered. The filtrate was stirred with a small amount of sodium 20 hydride to remove any residual moisture. After filtration, the filtrate was condensed to afford a 21 pale yellow liquid $(5.7 \mathrm{~g}, 80.5 \%)$. The crude monomer was washed by Soxhlet extraction with 22 hexanes and further purified by distillation $\left(50{ }^{\circ} \mathrm{C}, 20-50\right.$ militorr (i.e., 2.7-6.7 Pa) $)$ to afford a 23 colorless liquid (4.5 g, 85.1\%). ${ }^{1} \mathrm{H}$ NMR ( $\delta$ in $\left.\mathrm{CDCl}_{3}, 400 \mathrm{MHz}, \mathrm{ppm}\right): 3.38 \mathrm{ppm}\left(\mathrm{s}, 3 \mathrm{H}, \mathrm{CH}_{3} \mathrm{O}-\right)$; 
13.60 ppm (s, $2 \mathrm{H}, \quad \mathrm{CH}_{3} \mathrm{OCH}_{2} \mathrm{CH}_{2}$-); 4.28 ppm (s, $\left.2 \mathrm{H},-\mathrm{OOCCH}_{2}-\right) .{ }^{13} \mathrm{C}\left\{{ }^{1} \mathrm{H}\right\} \mathrm{NMR}\left(\delta\right.$ in $\mathrm{CDCl}_{3}$,

$2125 \mathrm{MHz}$, ppm): $43.6 \mathrm{ppm}\left(\mathrm{CH}_{3} \mathrm{OCH}_{2} \mathrm{CH}_{2}-\right) ; 50.8 \mathrm{ppm}\left(\mathrm{CH}_{3} \mathrm{OCH}_{2} \mathrm{CH}_{2-}\right) ; 59.0 \mathrm{ppm}$

$3 \quad\left(\mathrm{CH}_{3} \mathrm{OCH}_{2} \mathrm{CH}_{2}-\right) ; 70.9$ ppm $\left(-\mathrm{OOCCH}_{2}-\right) ; 152.2$ ppm $\quad\left(-\mathrm{CH}_{2} \mathrm{OCOOC}-\right) ; 163.8$ ppm (-

$4 \quad \mathrm{CH}_{2} \mathrm{OCOOC}$-). HRMS (ESI-TOF) $\mathrm{m} / z$ calcd for $\mathrm{C}_{6} \mathrm{H}_{10} \mathrm{NO}_{4}[\mathrm{M}+\mathrm{H}]^{+}$160.0604; found 160.0598.

$5 \mathrm{Me}(\mathrm{OEt})_{2}$-NCA $\left(\mathbf{M}_{\mathbf{2}}\right)$ in $60.9-63.8 \%$ yield was synthesized by the same procedure as that for

6 compound $\mathbf{M}_{\mathbf{1}} \cdot{ }^{1} \mathrm{H}$ NMR ( $\delta$ in $\mathrm{CDCl}_{3}, 400 \mathrm{MHz}, \mathrm{ppm}$ ): $4.34 \mathrm{ppm}\left(\mathrm{s}, 2 \mathrm{H},-\mathrm{OOCCH}_{2}\right.$ ); 3.51-3.72

7 ppm (m, 8H, $\left.-\mathrm{CH}_{2} \mathrm{CH}_{2} \mathrm{OCH} \mathrm{CH}_{2} \mathrm{O}-\right)$; $3.38 \mathrm{ppm}\left(-\mathrm{OCH}_{3}\right) .{ }^{13} \mathrm{C}\left\{{ }^{1} \mathrm{H}\right\} \mathrm{NMR}\left(\delta\right.$ in $\mathrm{CDCl}_{3}, 125 \mathrm{MHz}$,

8 ppm): 166.1 ppm (-COOCO-); 152.3 ppm (-COOCO-); 69.4-71.7 ppm (-OOCCH $2_{2-},-$

$\left.9 \mathrm{CH}_{2} \mathrm{CH}_{2} \mathrm{OCH}_{2} \mathrm{CH}_{2} \mathrm{O}-\right) ; 59.1$ ppm $\left(-\mathrm{CH}_{2} \mathrm{CH}_{2} \mathrm{OCH}_{2} \mathrm{CH}_{2} \mathrm{O}-\right) ; 50.9$ ppm $\left(-\mathrm{CH}_{2} \mathrm{CH}_{2} \mathrm{OCH}_{2} \mathrm{CH}_{2} \mathrm{O}-\right)$;

$1043.5 \mathrm{ppm}\left(-\mathrm{OCH}_{3}\right) . \mathrm{Me}(\mathrm{OEt})_{3}$-NCA $\left(\mathbf{M}_{3}\right)$ in $61.1-64.6 \%$ yield was synthesized by the same 11 procedure as that for compound $\mathbf{M}_{\mathbf{1}}$ and $\mathbf{M}_{2}$. HRMS (ESI-TOF) $m / z$ calcd for $\mathrm{C}_{8} \mathrm{H}_{14} \mathrm{NO}_{5}[\mathrm{M}+\mathrm{H}]^{+}$ 12 204.0866; found 204.0868. ${ }^{1} \mathrm{H}$ NMR ( $\delta$ in $\mathrm{CDCl}_{3}, 400 \mathrm{MHz}, \mathrm{ppm}$ ): $4.38 \mathrm{ppm}$ (s, $2 \mathrm{H},-\mathrm{OOCCH}_{2}$ ); 13 3.71-3.73 ppm (m, $\left.2 \mathrm{H}, \mathrm{CH}_{3} \mathrm{OCH}_{2}-\right)$; 3.59-3.66 ppm (m, 8H, $\mathrm{CH}_{3} \mathrm{OCH}_{2} \mathrm{CH}_{2} \mathrm{OCH}_{2} \mathrm{CH}_{2} \mathrm{OCH}_{2}$ ); 14 3.53-3.56 ppm (m, 2H, $\left.\mathrm{CH}_{3} \mathrm{OCH}_{2} \mathrm{CH}_{2} \mathrm{OCH}_{2} \mathrm{CH}_{2} \mathrm{OCH}_{2} \mathrm{CH}_{2}-\right) ; 3.39 \mathrm{ppm}\left(\mathrm{CH}_{3} \mathrm{O}-\right) .{ }^{13} \mathrm{C}\left\{{ }^{1} \mathrm{H}\right\} \mathrm{NMR}$ 15 ( $\delta$ in $\left.\mathrm{CDCl}_{3}, 125 \mathrm{MHz}, \mathrm{ppm}\right): 166.1 \mathrm{ppm}$ (-COOCO-); 152.4 ppm (-COOCO-); 69.4-70.5 ppm $16\left(\mathrm{CH}_{3} \mathrm{OCH}_{2} \mathrm{CH}_{2} \mathrm{OCH}_{2^{-}}\right) ; 71.9$ ppm (-OOCCH2-); 59.0 ppm $\left(\mathrm{CH}_{3} \mathrm{OCH}_{2} \mathrm{CH}_{2} \mathrm{OCH}_{2} \mathrm{CH}_{2^{-}}\right) ; 50.9$ 17 ppm $\left(\mathrm{CH}_{3} \mathrm{OCH}_{2} \mathrm{CH}_{2} \mathrm{OCH}_{2} \mathrm{CH}_{2} \mathrm{OCH}_{2} \mathrm{CH}_{2}-\right) ; 43.5$ ppm $\left(\mathrm{CH}_{3} \mathrm{OCH}_{2} \mathrm{CH}_{2} \mathrm{OCH}_{2} \mathrm{CH}_{2} \mathrm{OCH}_{2} \mathrm{CH}_{2}-\right)$. 18 HRMS (ESI-TOF) $\mathrm{m} / z$ calcd for $\mathrm{C}_{10} \mathrm{H}_{17} \mathrm{NO}_{6} \mathrm{Na}[\mathrm{M}+\mathrm{Na}]^{+} 270.0948$; found 270.0952 .

Representative synthetic procedure for PNMeOEtG. In the glovebox, $\mathbf{M}_{\mathbf{1}}(56.9 \mathrm{mg}$, $\left.200.36 \mathrm{mmol},[\mathrm{M}]_{0}=1 \mathrm{~mol} / \mathrm{L}\right)$ was dissolved in anhydrous THF $(201 \mu \mathrm{L})$. A volume of $21 \mathrm{BnNH}_{2} /$ THF stock solution $\left(157 \mu \mathrm{L}, 91.2 \mathrm{mM},[\mathrm{M}]_{0}:\left[\mathrm{BnNH}_{2}\right]_{0}=25: 1\right)$ was added to the 22 monomer solution and heated at $50{ }^{\circ} \mathrm{C}$ for $24 \mathrm{~h}$ under nitrogen atmosphere to reach quantitative 23 conversion as verified by FT-IR or NMR spectroscopy. The polymerization was quenched by 
1 adding excess hexanes. The precipitate was collected and washed with hexanes, followed by

2 drying under vacuum to obtain a crispy solid. Freeze drying yielded a white fluffy solid (34.1 mg, 3 82.3\%). ${ }^{1} \mathrm{H}$ NMR ( $\delta$ in $\left.\mathrm{D}_{2} \mathrm{O}, 400 \mathrm{MHz}, \mathrm{ppm}\right)$ : 7.25-7.33 ppm and 2.77-2.82 ppm (benzyl end 4 group); 4.01-4.53 ppm (m, $\left.-\mathrm{COCH}_{2}-\right) ; 3.49-3.83$ ppm (m, - $\left.\mathrm{CH}_{2} \mathrm{CH}_{2} \mathrm{OCH}_{3}\right) ; 3.02-3.31(\mathrm{~d}$, $\left.5 \mathrm{CH}_{2} \mathrm{CH}_{2} \mathrm{OCH}_{3}\right) \cdot{ }^{13} \mathrm{C}\left\{{ }^{1} \mathrm{H}\right\} \mathrm{NMR}\left(\delta\right.$ in $\left.\mathrm{CDCl}_{3}, 125 \mathrm{MHz}, \mathrm{ppm}\right): 169.0-169.8$ ppm $\left(-\mathrm{COCH}_{2}-\right)$, 6 71.0-71.4 ppm (- $\left.\mathrm{COCH}_{2}-\right), 69.9$ ppm $\left(-\mathrm{CH}_{2} \mathrm{CH}_{2} \mathrm{OCH}_{3}\right)$, 58.6-59.1 ppm $\left(-\mathrm{CH}_{2} \mathrm{CH}_{2} \mathrm{OCH}_{3}\right)$, 47.2-

$750.0 \mathrm{pm}\left(-\mathrm{OCH}_{3}\right)$. (PNMe $(\mathrm{OEt})_{2} \mathrm{G}$ (pale yellow sticky liquid) in $87.8-89.1 \%$ yield was 8 synthesized by the same procedure as that for PNMeOEtG. ${ }^{1} \mathrm{H}$ NMR ( $\delta$ in $\left.\mathrm{D}_{2} \mathrm{O}, 400 \mathrm{MHz}, \mathrm{ppm}\right)$ : $9 \quad$ 7.22-7.32 ppm and 2.93-2.94 ppm (benzyl end group); 4.09-4.63 ppm (m, 2H, -COCH $\left.2_{2}^{-}\right)$; 3.51$103.60 \mathrm{ppm}\left(\mathrm{m}, 8 \mathrm{H},-\mathrm{CH}_{2} \mathrm{CH}_{2} \mathrm{OCH}_{2} \mathrm{CH}_{2} \mathrm{OCH}_{3}\right) ; 3.26-3.28\left(\mathrm{~m},-\mathrm{OCH}_{3}\right) .{ }^{13} \mathrm{C}\left\{{ }^{1} \mathrm{H}\right\} \mathrm{NMR}\left(\delta\right.$ in $\mathrm{CDCl}_{3}$, $11125 \mathrm{MHz}, \mathrm{ppm}):$ 169.3-169.8 ppm $\left(-\mathrm{COCH}_{2}-\right), 71.8 \mathrm{ppm}\left(-\mathrm{COCH}_{2}-\right), 68.3-71.8 \mathrm{ppm}$ ($\left.12 \mathrm{CH}_{2} \mathrm{OCH}_{2} \mathrm{CH}_{2} \mathrm{OCH}_{3}\right), \quad 58.9$ ppm $\quad\left(-\mathrm{CH}_{2} \mathrm{CH}_{2} \mathrm{OCH}_{2} \mathrm{CH}_{2} \mathrm{OCH}_{3}\right), \quad 48.0-49.9$ ppm $\quad\left(-\mathrm{OCH}_{3}\right)$. 13 (PNMe $(\mathrm{OEt})_{3} \mathrm{G}$ (pale yellow sticky liquid) in $86.9-89.5 \%$ yield was synthesized by the same 14 procedure as that for PNMeOEtG and PNMe(OEt) $)_{2} \mathrm{G} .{ }^{1} \mathrm{H}$ NMR ( $\delta$ in $\left.\mathrm{D}_{2} \mathrm{O}, 400 \mathrm{MHz}, \mathrm{ppm}\right)$ : 15 7.24-7.32 ppm(benzyl end group); 4.10-4.55 ppm (m, 2H, -COCH $\left.2_{2}^{-}\right) ; 3.53-3.59$ ppm (m, 12H, $\left.16 \mathrm{CH}_{2} \mathrm{CH}_{2} \mathrm{OCH}_{2} \mathrm{CH}_{2} \mathrm{OCH}_{2} \mathrm{CH}_{2} \mathrm{OCH}_{3}\right) ; 3.29\left(\mathrm{~m},-\mathrm{OCH}_{3}\right) .{ }^{13} \mathrm{C}\left\{{ }^{1} \mathrm{H}\right\} \mathrm{NMR}\left(\delta\right.$ in $\mathrm{CDCl}_{3}, 125 \mathrm{MHz}$, 17 ppm): $\quad 169.2-169.8$ ppm $\quad\left(-\mathrm{COCH}_{2}-\right), \quad 71.9 \quad \mathrm{ppm} \quad\left(-\mathrm{COCH}_{2}-\right), \quad 68.4-70.5 \quad \mathrm{ppm} \quad(-$ $\left.18 \mathrm{CH}_{2} \mathrm{OCH}_{2} \mathrm{CH}_{2} \mathrm{OCH}_{2} \mathrm{CH}_{2} \mathrm{OCH}_{3}\right), 59.0$ ppm $\left(-\mathrm{CH}_{2} \mathrm{CH}_{2} \mathrm{OCH}_{2} \mathrm{CH}_{2} \mathrm{OCH}_{2} \mathrm{CH}_{2} \mathrm{OCH}_{3}\right), 48.0-49.9$ ppm $19\left(-\mathrm{OCH}_{3}\right)$.

Kinetic studies of $\mathrm{BnNH}_{2}$-initiated ring-opening polymerization of $\mathrm{Me}(\mathrm{OEt})_{\mathrm{n}}-\mathrm{NCA}$

21 (n = 1-3) $\left(\mathbf{M}_{1}, \mathbf{M}_{2}\right.$ and $\left.\mathbf{M}_{3}\right)$. A predetermined amount of $\mathrm{BnNH}_{2}$ stock solutions in toluene- $\mathrm{d}_{8}$ 22 were added to a toluene- $\mathrm{d}_{8}$ solution of $\mathrm{Me}(\mathrm{OEt})_{\mathrm{n}}-\mathrm{NCA}(\mathrm{n}=1-3)\left([\mathrm{M}]_{0}=0.2 \mathrm{~mol} / \mathrm{L}\right.$, $\left.23[\mathrm{M}]_{0}:\left[\mathrm{BnNH}_{2}\right]_{0}=25: 1\right)$ at room temperature followed by transferring into a resealable J-Young 
1 NMR tube. ${ }^{1} \mathrm{H}$ NMR spectra were collected every $3 \mathrm{~min} 44 \mathrm{~s}$ at $50{ }^{\circ} \mathrm{C}$ to determine the

2 conversion of monomers for more than four half-lives. Kinetic experiments were repeated twice

3 for each monomer.

4 Studies of $\boldsymbol{M}_{\mathbf{n}}$ versus polymerization conversion. The polymerization of $\mathrm{Me}(\mathrm{OEt})_{\mathrm{n}^{-}}$ 5 NCA $(\mathrm{n}=1-3)\left(\mathbf{M}_{1}, \mathbf{M}_{2}\right.$ and $\left.\mathbf{M}_{3}\right)$ was conducted in $\mathrm{THF}$ at $50{ }^{\circ} \mathrm{C}\left([\mathrm{M}]_{0}:[\mathrm{I}]_{0}=50: 1,[\mathrm{M}]_{0}=1\right.$ $6 \mathrm{~mol} / \mathrm{L}$ ) and aliquots were taken at different time intervals and analyzed by ${ }^{1} \mathrm{H}$ NMR spectroscopy

7 to determine the conversion. The aliquots taken at different time intervals were further analyzed 8 with MALDI-TOF mass spectrometry to obtain the polymer molecular weight $\left(M_{\mathrm{n}}\right)$ and 9 molecular weight distribution (PDI). The obtained $M_{\mathrm{n}} \mathrm{s}$ were plotted against the corresponding 10 polymerization conversion.

Cytotoxicity study. The cytotoxicity study was conducted by adapting a reported

12 procedure. $^{56}$ The HEp2 cells were plated at 8600 cells per well in a Costar 96-well plate (BD 13 biosciences) and allowed to grow for $48 \mathrm{~h}$. The polypeptoids were dissolved in Eagle's Minimum 14 Essential Medium (EMEM) and diluted to final working concentrations $(0,0.0625,0.125,0.25$, 150.5 , and $1.0 \mathrm{mg} / \mathrm{mL}$ ). The cells were exposed to the working solutions of the polypeptoids in 16 varying concentration and incubated for $24 \mathrm{~h}\left(37{ }^{\circ} \mathrm{C}, 95 \%\right.$ humidity, $\left.5 \% \mathrm{CO}_{2}\right)$. The working 17 solutions were removed, and the cells were washed with 1x PBS. The medium containing $20 \%$ 18 CellTiter Blue (Promega) was added and incubated for $4 \mathrm{~h}$. The viability of cells is measured by 19 reading the fluorescence of the medium at an excitation wavelength of $570 \mathrm{~nm}$ and an emission 20 wavelength of $595 \mathrm{~nm}$ using a BMG FLUOstar Optima micro-plate reader. In this assay, the 21 indicator dye resazurin is reduced to fluorescent resorufin in viable cells, while non-viable cells 22 are not able to reduce resazurin nor to generate a fluorescent signal. The fluorescence signal of 
1 viable (untreated) cells was normalized to $100 \%$. The mean values are obtained from triplicate

2 measurements.

3

4

5

6

7 moderate overall yields $(31.3-46.6 \%)$ in four steps by adapting a reported procedure ${ }^{57-58}$ as

8 outlined in Scheme 1. The monomer precursors (3, 7 and 11) exhibit as two sets of rotamers at $925{ }^{\circ} \mathrm{C}$ in $\mathrm{CDCl}_{3}$ due to restricted rotation of the amide bond, as supported by the merging and 10 broadening of the two sets of ${ }^{1} \mathrm{H}$ NMR signals at elevated temperature $\left(50{ }^{\circ} \mathrm{C}\right)$ (Figure S5, S12 11 and S21). The chemical structures of the desired monomers $\left(\mathbf{M}_{1}, \mathbf{M}_{2}\right.$ and $\left.\mathbf{M}_{3}\right)$ were confirmed by $12 \quad{ }^{1} \mathrm{H}$ and ${ }^{13} \mathrm{C}\left\{{ }^{1} \mathrm{H}\right\}$ NMR spectroscopy analysis (Figure 1, S14-S15 and S23-S24). The polypeptoids 13 bearing oligomeric ethylene glycol side chains $\left(\mathrm{PNMe}(\mathrm{OEt})_{\mathrm{n}} \mathrm{G}, \mathrm{n}=1-3\right)$ were synthesized by 14 ring-opening polymerizations of their corresponding monomers $\left(\mathbf{M}_{1}, \mathbf{M}_{\mathbf{2}}\right.$ and $\left.\mathbf{M}_{3}\right)$ using benzyl 15 amine initiators (Scheme 2). Polymerization reactions were conducted at different initial 16 monomer to initiator ratios $\left([\mathrm{M}]_{0}:[\mathrm{I}]_{0}\right)$ in anhydrous $\mathrm{THF}$ at $50{ }^{\circ} \mathrm{C}$ for $24-48 \mathrm{~h}$ to reach 17 quantitative conversion. The polymers were purified by precipitation in hexanes and collected by 18 filtration followed by drying under vacuum to yield ether crispy white solids (PNMeOEtG) or 19 viscous liquids (PNMe $\left.(\mathrm{OEt})_{\mathrm{n}} \mathrm{G}, \mathrm{n}=2-3\right)$ in good yields (82.3-87.8\%). The number-averaged 20 molecular weight $\left(M_{\mathrm{n}}\right)$ and degree of polymerization $\left(\mathrm{DP}_{\mathrm{n}}\right)$ of the polymer were determined by 21 both end-group analysis using ${ }^{1} \mathrm{H}$ NMR spectroscopy and SEC-MALS-DRI analysis using the 22 measured $\mathrm{d} n / \mathrm{d} c$ values of the polymers. For example, the $\mathrm{DP}_{\mathrm{n}}$ and $M_{\mathrm{n}}$ of PNMeOEtG were 23 determined by the integrations at $4.01-4.52 \mathrm{ppm}$ due to the methylene group in the backbone 
1 relative to the integration of signals at $7.3 \mathrm{ppm}$ due to the benzyl end-group (Figure 2). The

2 PNMe $(\mathrm{OEt})_{\mathrm{n}} \mathrm{G}(\mathrm{n}=1-3)$ were also characterized by ${ }^{13} \mathrm{C}\left\{{ }^{1} \mathrm{H}\right\}$ NMR spectroscopy (Figure 2, S26-

3 28). The molecular weight of the polymers $\left(M_{\mathrm{n}}\right)$ was shown to increase as the initial monomer to

4 initiator ratio $\left([\mathrm{M}]_{0}:[\mathrm{I}]_{0}\right)$ was systematically increased (Table 1$)$. The polymer molecular weights

$5 \quad\left(M_{\mathrm{n}}\right)$ agreed well with the theoretically predicted values at low molecular weight range $\left([\mathrm{M}]_{0}:[\mathrm{I}]_{0}\right.$

$6<200: 1)$. However, at high $[\mathrm{M}]_{0}:[\mathrm{I}]_{0}$ ratios (200:1 and 400:1), the molecular weight of the

7 polymers $\left(M_{\mathrm{n}}\right)$ determined from SEC analysis deviated from the theoretical values presumably

8 due to the presence of nucleophilic impurities which can initiate the polymerization of these

9 monomers. The polymer molecular weight distributions were narrow with low polydispersity

10 indices (PDI) in the 1.03-1.10 range (Table 1, Figure 3, S31 and S33) as determined by SEC-

11 MALS-DRI analysis in $0.1 \mathrm{~mol} / \mathrm{L} \mathrm{LiBr} / \mathrm{DMF}$ at room temperature $\left(20{ }^{\circ} \mathrm{C}\right)$. Similar $M_{\mathrm{n}}$ and PDI

12 control was also observed for the polymerization of MeOEt-NCA conducted in toluene under

13 identical conditions (Table S1). The structure of low molecular weight PNMe $(\mathrm{OEt})_{\mathrm{n}} \mathrm{G}(\mathrm{n}=1-3)$

14 was further confirmed by MALDI-TOF MS analysis. The MS spectra revealed a symmetric

15 monomodal set of mass ions where $\mathrm{m} / \mathrm{z}$ equals to integral numbers of the desired repeating unit 16 mass $(115.1,159.1$ and $203.1 \mathrm{~g} / \mathrm{mol})$ for $\left(\mathrm{PNMe}(\mathrm{OEt})_{\mathrm{n}} \mathrm{G}, \mathrm{n}=1-3\right)$ plus 22.99 or 38.96 for sodium

17 or potassium ion. This is consistent with the targeted polypeptoid structures bearing one benzyl 18 amide and one secondary amine chain end (Scheme 2), in support of controlled polymerization 19 initiated by benzyl amine initiator. (Figure 4, S30 and S32). In addition, a minor set of mass ions 20 that are consistent with polypeptoid structures having acyl chloride and amine end-group 21 structures are visible in the expanded spectrum of PNMe $(\mathrm{OEt})_{2} \mathrm{G}$ (Figure $\mathrm{S} 30 \mathrm{C}$ ), indicating $\mathrm{Cl}^{-}$ 22 ions are potential impurities that can initiate the polymerization of the NCAs. 
1 Scheme1. Synthetic procedures of Me(OEt $)_{n}-N C A(n=1-3)$.

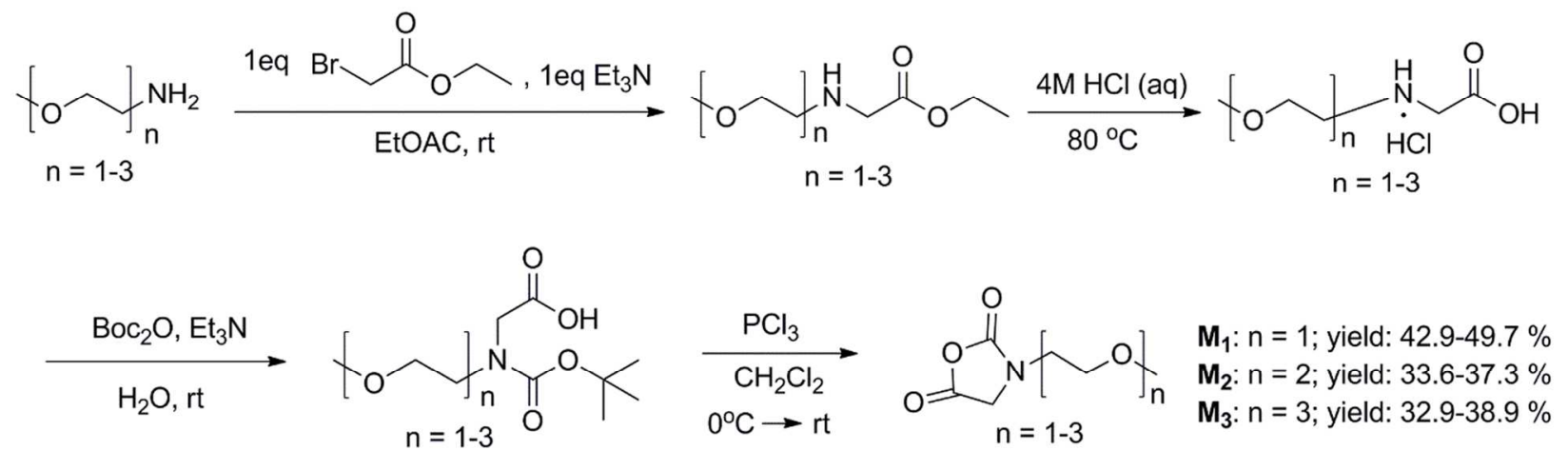

2

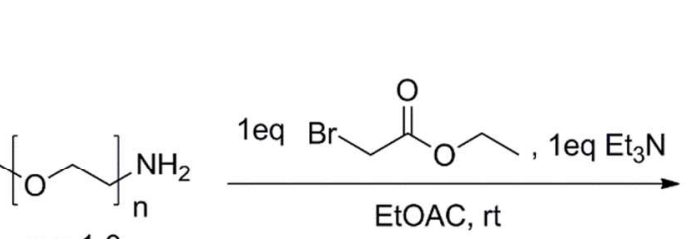

$M_{3}: n=3$; yield: $32.9-38.9 \%$

3
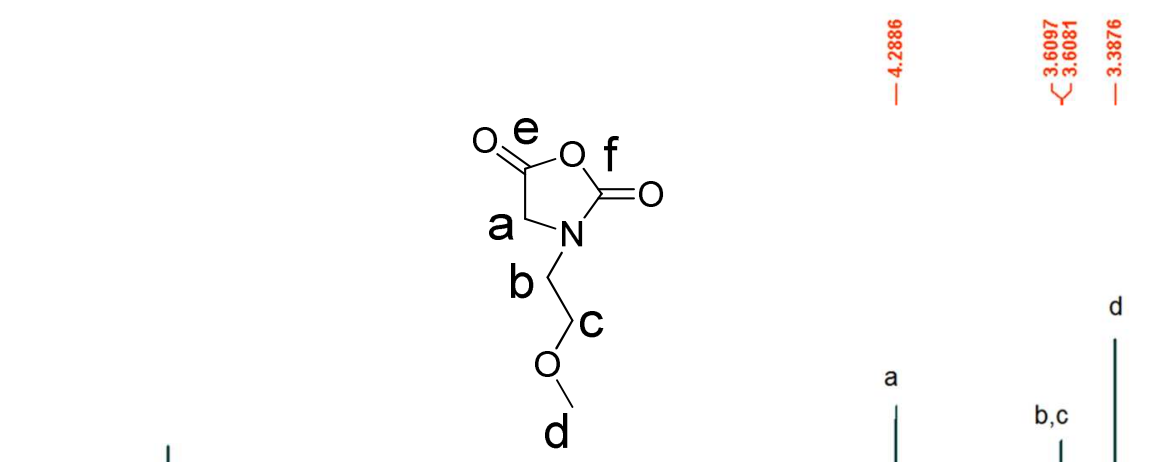

23

24

25

26

27

28

29

31

32

33

34

35

36

37

38

39

40

41

42

43

44

45

46

47

48

49

50 
1<smiles>CC(C)(C)OCC(C)(C)N1CC(=O)OC1=O</smiles>
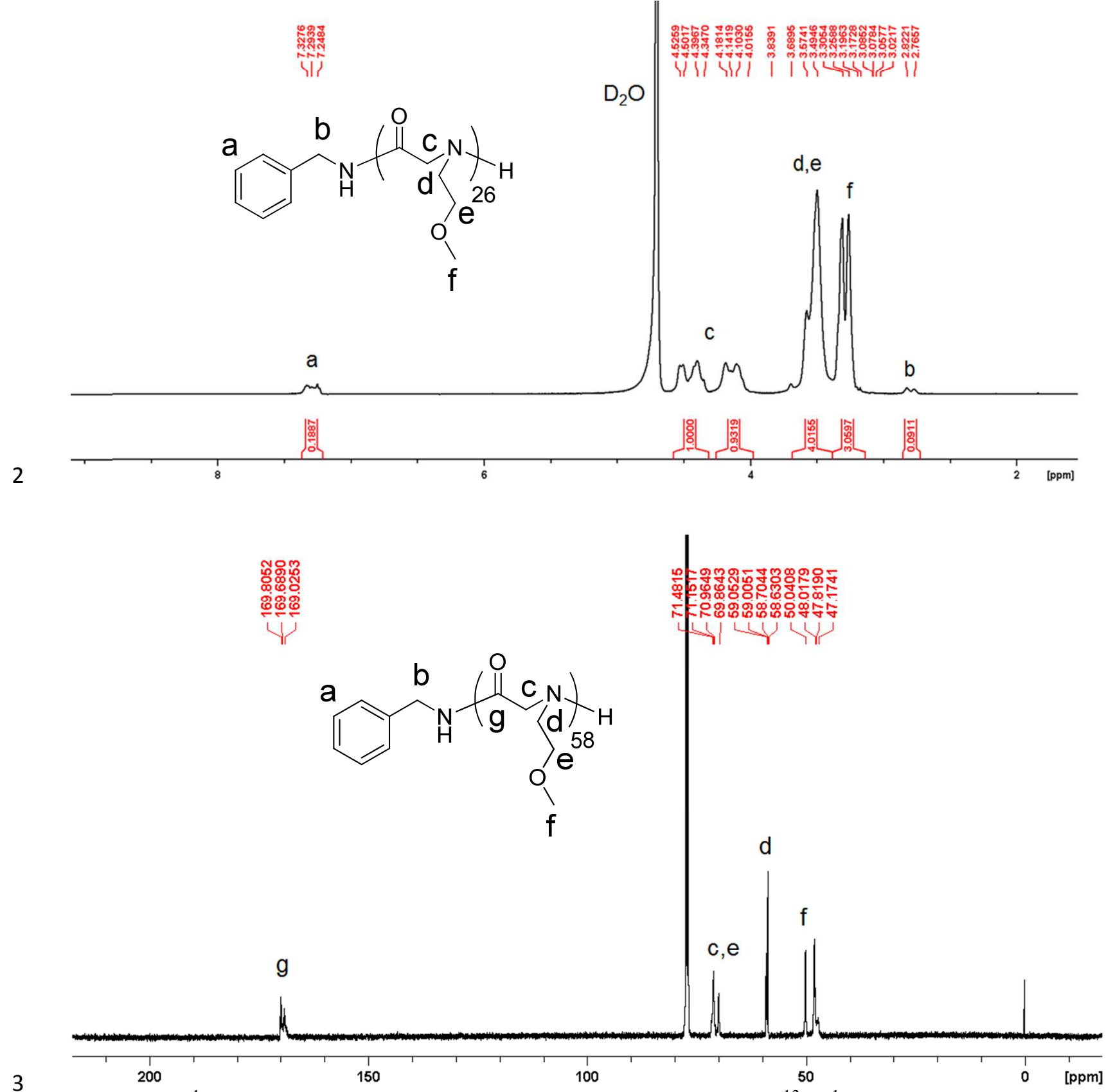

4 Figure 2. ${ }^{1} \mathrm{H}$ NMR spectrum of $\mathrm{PNMeOEtG}_{26}$ in $\mathrm{D}_{2} \mathrm{O}$ and $\left.{ }^{13} \mathrm{C}\left\{{ }^{1} \mathrm{H}\right\}\right) \mathrm{NMR}$ spectrum of $5 \quad \mathrm{PNMeOEtG}_{58}$ in $\mathrm{CDCl}_{3}$. 


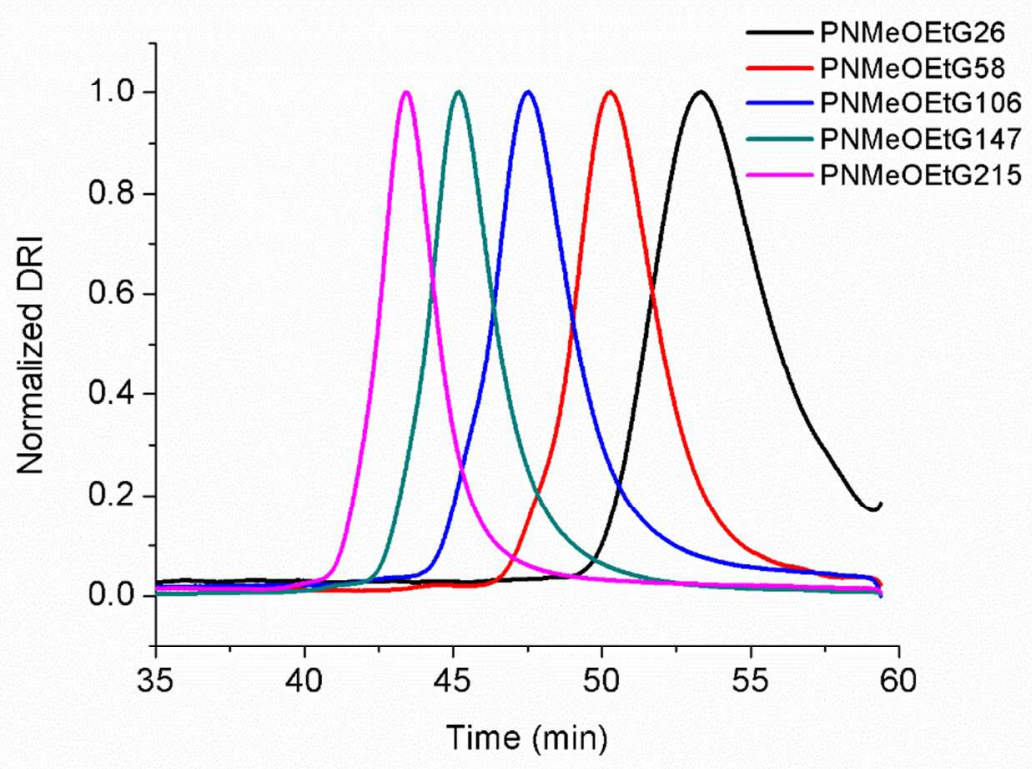

1

2 Figure 3. SEC-DRI chromatograms of PNMeOEtG polymers prepared from benzyl amine3 initiated polymerization of MeOEt-NCA $\left(\mathbf{M}_{1}\right)\left(\left[\mathrm{M}_{1}\right]_{0}:\left[\mathrm{BnNH}_{2}\right]_{0}=25: 1(-), 50: 1(-), 100: 1(-\right.$ $4 \quad$ ), 200:1 (一), 400:1 (一), Table 1). The $\mathrm{DP}_{\mathrm{n}} \mathrm{s}$ listed in the figure were determined from the SEC5 MALS-DRI analysis of the polymers using the $\mathrm{d} n / \mathrm{d} c=0.0633(4) \mathrm{mL} / \mathrm{g}$ in $0.1 \mathrm{~mol} / \mathrm{L} \mathrm{LiBr} / \mathrm{DMF}$ 6 at $20^{\circ} \mathrm{C}$.
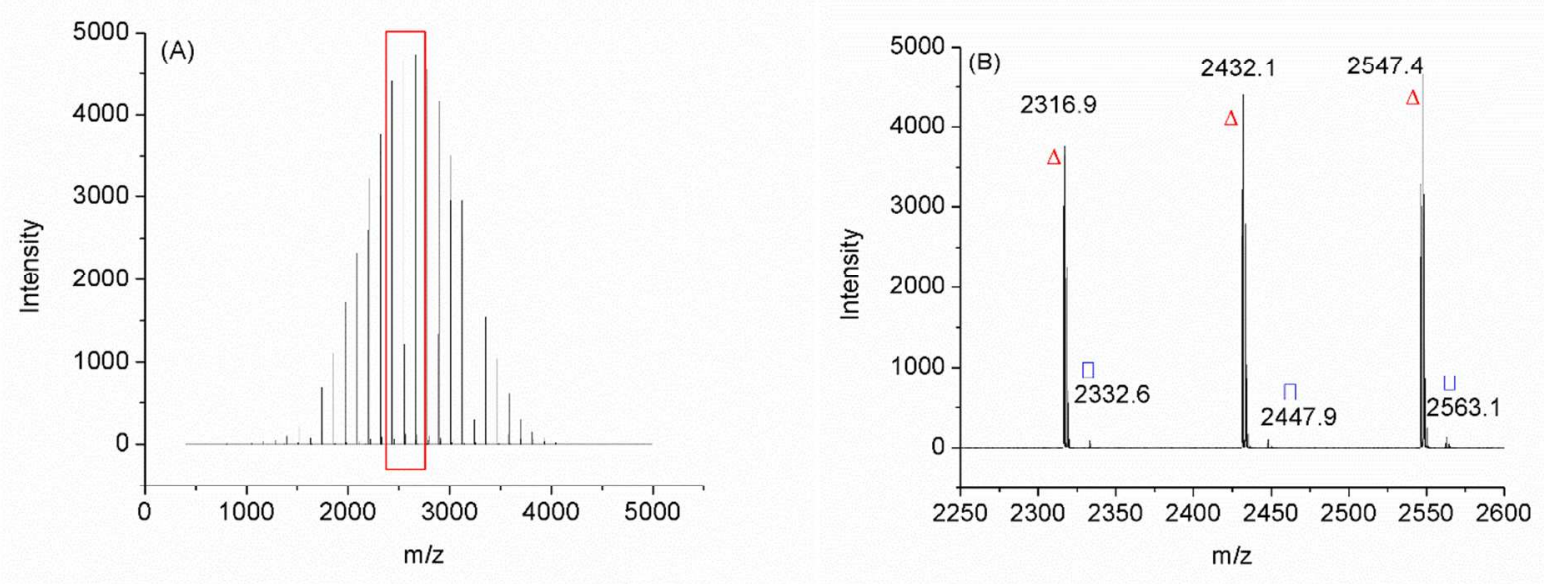
1

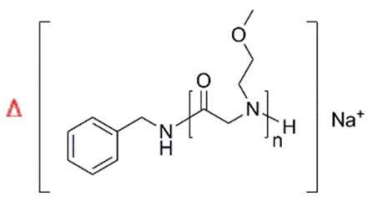

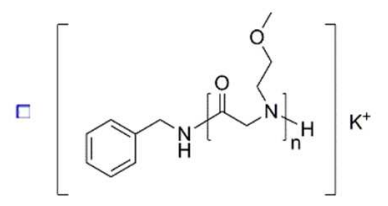

2 Figure 4. Representative full (A) and expanded MALDI-TOF MS (B) spectra of PNMeOEtG

$3 \quad\left(M_{\mathrm{n}}=2.7 \mathrm{~kg} / \mathrm{mol}, \mathrm{PDI}=1.03\right.$, matrix: $\left.\mathrm{CHCA}\right)$.

4 Table 1. $\mathrm{BnNH}_{2}$-initiated ROP of $\mathrm{MeOEt}-\mathrm{NCA}\left(\mathbf{M}_{\mathbf{1}}\right), \mathrm{Me}(\mathrm{OEt})_{2}-\mathrm{NCA}\left(\mathbf{M}_{2}\right)$ and $\mathrm{Me}(\mathrm{OEt})_{2^{-}}$

$5 \operatorname{NCA}\left(\mathbf{M}_{3}\right) \cdot{ }^{a}$

\begin{tabular}{|c|c|c|c|c|c|c|c|c|}
\hline \multirow{7}{*}{ PNMeOEtG } & \multirow[b]{2}{*}{ Entry } & \multirow[b]{2}{*}[\mathrm{M}]{$_{0} /[\mathrm{I}]_{0}$} & \multirow{2}{*}{$\begin{array}{c}M_{\mathrm{n}}(\text { theor. }) \\
(\mathrm{kg} / \mathrm{mol})^{b}\end{array}$} & \multicolumn{2}{|c|}{$M_{\mathrm{n}}(\mathrm{kg} / \mathrm{mol})$} & \multirow[b]{2}{*}{$\mathrm{PDI}^{c}$} & \multirow{2}{*}{$\begin{array}{l}\text { Reaction } \\
\text { time (h) }\end{array}$} & \multirow{2}{*}{$\frac{\text { Conv. }(\%)}{100}$} \\
\hline & & & & $\mathrm{SEC}^{c}$ & $\mathrm{NMR}^{d}$ & & & \\
\hline & 1 & $25: 1$ & 2.98 & 3.26 & 3.09 & 1.10 & 24 & 100 \\
\hline & 2 & $50: 1$ & 5.86 & 6.26 & 6.32 & 1.08 & 24 & 100 \\
\hline & 3 & $100: 1$ & 11.6 & 11.1 & 12.4 & 1.05 & 24 & 100 \\
\hline & 4 & $200: 1$ & 23.1 & 17.0 & 24.6 & 1.04 & 48 & 100 \\
\hline & 5 & $400: 1$ & 46.1 & 24.8 & $-e$ & 1.04 & 48 & 100 \\
\hline \multirow{5}{*}{$\mathrm{PNMe}(\mathrm{OEt})_{2} \mathrm{G}$} & 1 & $25: 1$ & 4.08 & 4.03 & 4.24 & 1.06 & 24 & 100 \\
\hline & 2 & $50: 1$ & 8.06 & 8.57 & 8.69 & 1.09 & 24 & 100 \\
\hline & 3 & $100: 1$ & 16.0 & 13.5 & 16.3 & 1.03 & 48 & 100 \\
\hline & 4 & $200: 1$ & 31.9 & 18.9 & 33.9 & 1.04 & 48 & 100 \\
\hline & 5 & $400: 1$ & 63.7 & 26.8 & $-^{e}$ & 1.05 & 48 & 100 \\
\hline \multirow{5}{*}{$\mathrm{PNMe}(\mathrm{OEt})_{3} \mathrm{G}$} & 1 & $25: 1$ & 5.18 & 5.29 & 5.18 & 1.07 & 24 & 100 \\
\hline & 2 & $50: 1$ & 10.3 & 9.34 & 11.7 & 1.05 & 24 & 100 \\
\hline & 3 & $100: 1$ & 20.4 & 16.9 & 21.6 & 1.07 & 48 & 100 \\
\hline & 4 & $200: 1$ & 40.7 & 24.2 & 41.3 & 1.06 & 48 & 100 \\
\hline & 5 & $400: 1$ & 81.3 & 30.0 & $-^{e}$ & 1.08 & 48 & 100 \\
\hline
\end{tabular}

6

7

8

9

10

11

12

13

14

15

16

17

a. All the polymerizations were conducted in THF at $50{ }^{\circ} \mathrm{C}$ with $[\mathrm{M}]_{0}=1.0 \mathrm{~mol} / \mathrm{L}$. SEC analysis was conducted by directly injecting the polymerization solutions into SEC column after reaching quantitative conversion. ${ }^{b}$ Determined based on conversion and $[\mathrm{M}]_{0} /[\mathrm{I}]_{0}$ ratio. ${ }^{c}$. Determined from a tandem SECMALS-DRI system using the $\mathrm{d} n / \mathrm{d} c 0.0633(4) \mathrm{mL} / \mathrm{g}$ for PNMeOEtG, $0.0686(8) \mathrm{mL} / \mathrm{g}$ for PNMe $(\mathrm{OEt})_{2} \mathrm{G}$ and $0.0563(6) \mathrm{mL} / \mathrm{g}$ for $\mathrm{PNMe}(\mathrm{OEt})_{3} \mathrm{G}$ in $0.1 \mathrm{~mol} / \mathrm{L} \mathrm{LiBr} / \mathrm{DMF}$ at room temperature. ${ }^{d}$ Determined by the end-group analysis using ${ }^{1} \mathrm{H}$ NMR spectroscopy. ${ }^{e}$ The benzyl amine end-group content is too low to be accurately integrated and therefore the $M_{\mathrm{n}}$ cannot be reliably determined from the ${ }^{1} \mathrm{H}$ NMR end-group analysis.

Polymerization kinetics were investigated at a constant initial monomer to initiator ratio $\left([\mathrm{M}]_{0}:\left[B n N H_{2}\right]_{0}=25: 1,[\mathrm{M}]_{0}=0.2 \mathrm{~mol} / \mathrm{L}\right)$ in toluene- $\mathrm{d}_{8}$ at $50{ }^{\circ} \mathrm{C}$. The polymerizations of the three monomers all exhibited a first-order dependence on the monomer concentration (i.e., 
$1 \mathrm{~d}[\mathrm{M}] / \mathrm{dt}=k_{\mathrm{obs}}[\mathrm{M}]$ ), consistent with a living polymerization (Figure 5). As the number of ethylene

2 glycol unit on the monomer side chain increased from one (MeOEt-NCA, $\mathbf{M}_{1}$ ) to three

$3\left(\mathrm{Me}(\mathrm{OEt})_{3}-\mathrm{NCA}, \mathbf{M}_{3}\right)$, the observed rate constant $\left(k_{\mathrm{obs}}\right)$ of the polymerization decreased from

$40.01285( \pm 6)$ to $0.00291( \pm 7) \mathrm{min}^{-1}$. It was attributed to the enhanced steric hindrance and

5 electron-withdrawing effect associated with the increased number of ethylene glycol moiety on

6 the side chain (from $\mathbf{M}_{1}$ to $\mathbf{M}_{2}$ and $\mathbf{M}_{3}$ ), resulting in reduced nucleophilicity of the secondary

7 amino chain end and thus decreasing propagation rate. In addition, the plots of $M_{\mathrm{n}}$ of the

8 corresponding polypeptoids all exhibited a linear dependence on polymerization conversion

9 (Figure 5B and S33), indicating the presence of a constant concentration of propagation species

10 in accord with a living polymerization. The molecular weight distribution $(\mathrm{PDI}=1.01-1.18)$

11 determined by MALDI-TOF MS analysis remained relatively narrow throughout the course of 12 polymerization. 

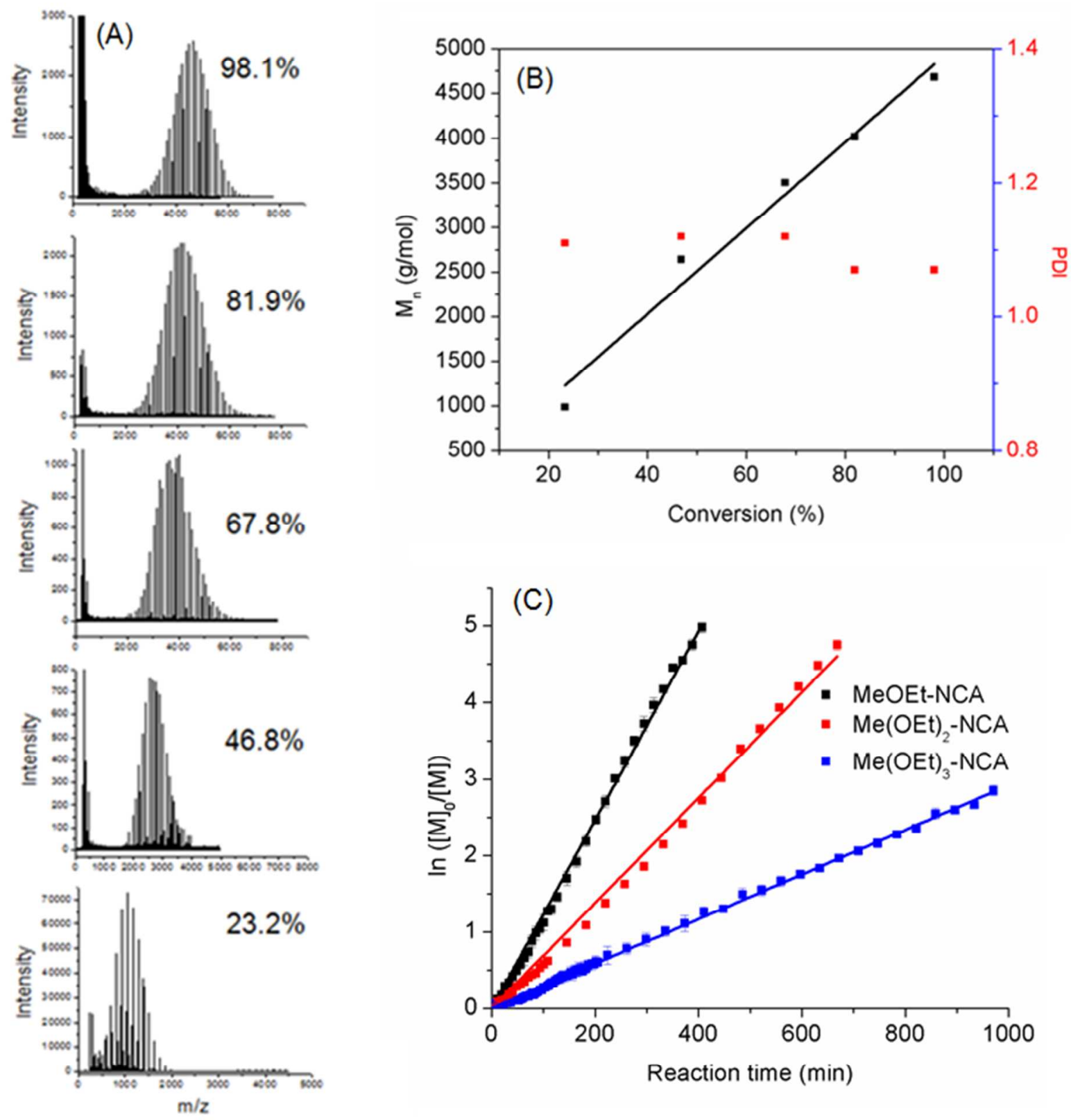

1

2 Figure 5. (A) MALDI-TOF MS spectra of PNMeOEtG (PDI = 1.07-1.11) at different

3 polymerization conversion. (B) Plots of $M_{\mathrm{n}}$ and PDI verses conversion for $\mathrm{BnNH}_{2}$-initiated

4 polymerization of MeOEt-NCA in THF $\left([\mathrm{M}]_{0}:[\mathrm{I}]_{0}=50: 1,[\mathrm{M}]_{0}=1 \mathrm{~mol} / \mathrm{L}\right)$. (C) Plots of $\ln$

$5\left([\mathrm{M}] /[\mathrm{M}]_{0}\right)$ versus the reaction time for the $\mathrm{BnNH}_{2}$-initiated polymerization of $\mathrm{Me}(\mathrm{OEt})_{\mathrm{n}}-\mathrm{NCA}(\mathrm{n}$

$6=1-3)\left([\mathrm{M}]_{0}:\left[\mathrm{BnNH}_{2}\right]=25: 1,[\mathrm{M}]_{0}=0.2 \mathrm{~mol} / \mathrm{L}\right.$, in toluene- $\mathrm{d}_{8}$ at $\left.50{ }^{\circ} \mathrm{C}\right)$. The error bars in $(\mathrm{C})$ are

7 the standard deviation of three measurements. 
DSC and TGA analysis of $\left(\operatorname{PNMe}(\mathrm{OEt})_{\mathbf{n}} \mathbf{G}, \mathbf{n}=\mathbf{1 - 3}\right)$. The PEGylated polypeptoids were

2 characterized by TGA and DSC. The TGA thermograms of PNMe $(\mathrm{OEt})_{\mathrm{n}} \mathrm{G} 100(\mathrm{n}=1-3)$ (Figure

36 (A), S34 and S35) revealed a three-stage decomposition profiles with a slow and gradual mass

4 loss at low temperatures $\left(25-100^{\circ} \mathrm{C}\right)$ which was attributed to the loss of small amount of water in

5 the samples due to the highly hygroscopic nature of these polymers, followed by a drastic mass

6 loss occurring at $250-400{ }^{\circ} \mathrm{C}$ for all three PEGylated polypeptoids and then a gradual decrease of

7 mass loss from $400-500{ }^{\circ} \mathrm{C}$. These data indicated the decomposition temperatures $\left(\mathrm{T}_{\mathrm{d}}\right)$ of the

8 three polymers are all higher than $250{ }^{\circ} \mathrm{C}$. As a result, the subsequent DSC analysis was

9 conducted in the temperature window between $-50{ }^{\circ} \mathrm{C}$ and $200{ }^{\circ} \mathrm{C}$. The DSC thermograms of the

10 three polymers from the second heating cycle are shown in Figure 6, S36 and S37. The absence

11 of melting and crystallization exothermic peaks indicates that all three PEGylated polypeptoids

$12\left(M_{\mathrm{n}}=3.26-16.9 \mathrm{~kg} / \mathrm{mol}\right)$ are amorphous, in agreement with the previously reported oligomeric

13 PEGylated peptoids. ${ }^{50}$ The $\mathrm{T}_{\mathrm{g}}$ values of the PEGylated polypeptoids (Table 2) decreased with

14 increasing the length of oligomeric ethylene glycol side chains PNMeOEtG $\left(\mathrm{T}_{\mathrm{g}}=24.5-46.4\right.$

$\left.15{ }^{\circ} \mathrm{C}\right)>\operatorname{PNMe}(\mathrm{OEt})_{2} \mathrm{G}\left(\mathrm{T}_{\mathrm{g}}=-5.8--15.8{ }^{\circ} \mathrm{C}\right)>\operatorname{PNMe}(\mathrm{OEt})_{3} \mathrm{G}\left(\mathrm{T}_{\mathrm{g}}=-34.9--41.1{ }^{\circ} \mathrm{C}\right)$, consistent

16 with the previously reported observations for the oligomeric analogs. ${ }^{50}$ The decrease of $\mathrm{T}_{\mathrm{g}}$ with

17 increasing side chain length has also been observed for comb-like polymers having $n$-alkyl side

18 chains of varying length and semi-flexible or rigid main chains. ${ }^{59}$ Dynamic asymmetry between

19 backbone and side chain have been attributed to the $T_{g}$ dependence on the side chain length. ${ }^{60-63}$

20 The $T_{g}$ values observed for all the PEGylated polypeptoids were significantly lower than that of

21 the amorphous poly $\left(N\right.$-methyl glycine) (a.k.a. polysarcosine) $\left(\mathrm{T}_{\mathrm{g}}=127-143{ }^{\circ} \mathrm{C}\right)$ and $\operatorname{poly}(N-$

22 ethyl glycine) $\left(\mathrm{T}_{\mathrm{g}}=93-114{ }^{\circ} \mathrm{C}\right)$ having comparable molecular weight. ${ }^{64}$ The $\mathrm{T}_{\mathrm{g}}$ values of the

23 polymer was shown to increase with the increase of the polymer molecular weight, which is 
1 attributed to the reduction of free volume due to the diminished chain-end content at increasing

2 molecular weight. ${ }^{65} \mathrm{~T}_{\mathrm{g}}$ of $\mathrm{PNMeOEtG}_{20}$ polymer $\left(\mathrm{T}_{\mathrm{g}}=24.5{ }^{\circ} \mathrm{C}, \mathrm{DP}_{\mathrm{n}}=20, \mathrm{PDI}=1.09\right)$ is about

$314{ }^{\circ} \mathrm{C}$ lower than the corresponding 20 mer $\left(\mathrm{T}_{\mathrm{g}}=38.6{ }^{\circ} \mathrm{C}\right.$, PDI $\left.<1.0003\right)$ obtained by the solid-

4 phase "submonomer" method. ${ }^{50}$ The discrepancy is presumably resulted from the difference in

5 end-group structures and polydispersity of the samples. As the chains are relative short, end-

6 group structural difference will contribute significantly to a difference in free volume and thus $\mathrm{T}_{\mathrm{g}}$.

7 The polymeric sample contains a mixture of chains that are shorter or longer than 20 mer in

8 varying amounts, which will have different $\mathrm{T}_{\mathrm{g}} \mathrm{s}$ due to free volume difference.
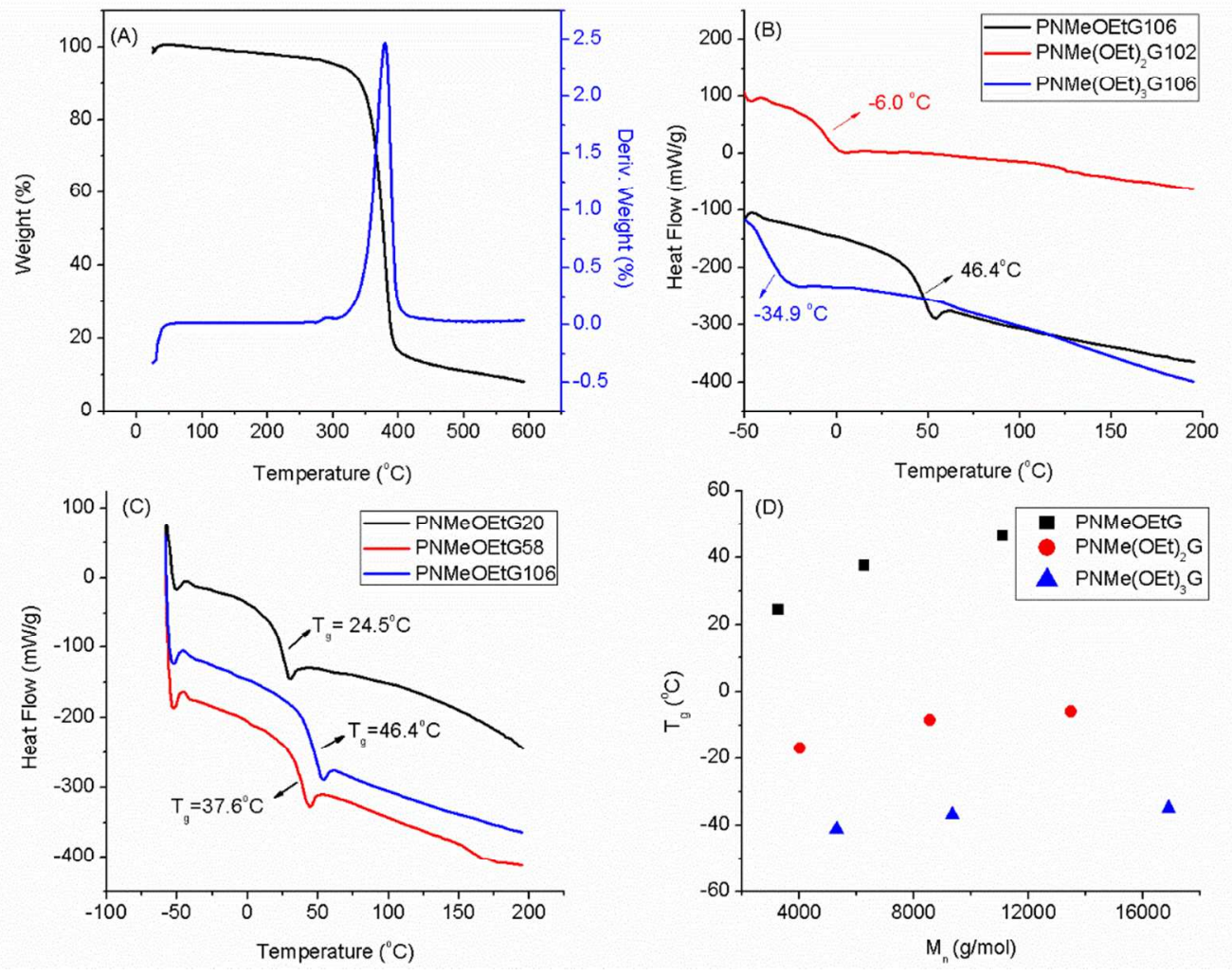

10 Figure 6. (A) Thermogravimetric analysis (TGA) of $\mathrm{PNMeOEtG}_{106}$. (B) DSC thermograms of $11 \mathrm{PNMe}(\mathrm{OEt})_{\mathrm{n}} \mathrm{G}(\mathrm{n}=1-3)$. (C) DSC thermograms of PNMeOEtG at different molecular weight 
1 during the second heating cycle. (D) Plot of $\mathrm{T}_{\mathrm{g}}$ verses $M_{\mathrm{n}}$ of $\mathrm{PNMe}(\mathrm{OEt})_{\mathrm{n}} \mathrm{G}(\mathrm{n}=1-3)$. The $\mathrm{DP}_{\mathrm{n}} \mathrm{S}$

2 listed in the figures were determined from the end-group analysis by ${ }^{1} \mathrm{H}$ NMR spectroscopy.

3

\begin{tabular}{|c|c|c|c|}
\hline Sample & $M_{\mathrm{n}}(\mathrm{kg} / \mathrm{mol})$ & $\mathrm{T}_{\mathrm{g}}\left({ }^{\circ} \mathrm{C}\right)$ & $\mathrm{T}_{\mathrm{d}}\left({ }^{\circ} \mathrm{C}\right)$ \\
\hline \multirow{3}{*}{$\mathrm{PNMeOEtG}$} & 2.41 & 24.5 & 378 \\
\cline { 2 - 4 } & 6.26 & 37.6 & 373 \\
\cline { 2 - 4 } & 11.1 & 46.4 & 375 \\
\hline \multirow{3}{*}{$\mathrm{PNMe}(\mathrm{OEt})_{2} \mathrm{G}$} & 4.03 & -15.8 & 345 \\
\cline { 2 - 4 } & 8.57 & -8.6 & 345 \\
\cline { 2 - 4 } & 13.5 & -5.8 & 360 \\
\hline \multirow{3}{*}{$\mathrm{PNMe}(\mathrm{OEt})_{3} \mathrm{G}$} & 5.29 & -41.1 & 374 \\
\cline { 2 - 4 } & 9.34 & -36.9 & 382 \\
\cline { 2 - 4 } & 16.9 & -34.9 & 377 \\
\hline
\end{tabular}

4

\section{Characterization of protein adsorption and interaction with PNMeOEtG by DLS}

analysis. As the PEGylated polypeptoids are highly water soluble, charge neutral and have hydrogen bond accepting groups both on the backbones and side chains, which fulfill all the criteria of the abovementioned "Whitesides rule" for protein-resistant materials, we hypothesized that the polymers may exhibit antifouling behaviors. PNMeOEtG was selected as the model polymer to study the protein resistant characteristics of the PEGylated polypeptoids. DLS was used to monitor the size change of PNMeOEtG, lysozyme and their mixture in PBS. Lysozyme was selected here as the model protein due to their comparable size with PNMeOEtG. An increase of hydrodynamic size would be expected for the mixture of lysozyme and PNMeOEtG in PBS if appreciable amount of lysozyme was absorbed to the polymer chains. The PNMeOEtG and lysozyme were found to be stable at their respective $1 \mathrm{wt} \%$ solution in PBS during a period of $24 \mathrm{~h}$, evidenced by no appreciable change of the hydrodynamic size distribution and the derived count rates (Figure S38 and S39). The mixture of lysozyme (1 wt\%) and PNMeOEtG (1 wt\%) in PBS also revealed no obvious hydrodynamic size increase during a period of $24 \mathrm{~h}$. 
1 Furthermore, the hydrodynamic sizes $\left(D_{h}=5.56 \pm 0.16 \mathrm{~nm}\right)$, derived count rates and

2 correlograms of the mixture lie in between that of $1 \mathrm{wt} \%$ PNMeOEtG $(6.39 \pm 0.09 \mathrm{~nm})$ and $1 \mathrm{wt} \%$

3 lysozyme $(4.69 \pm 0.25 \mathrm{~nm})$ individually in PBS, indicating there is no apparent adsorption of

4 lysozyme onto the polymers (Figure 8). For comparison purposes, PEG $\left(M_{\mathrm{n}}=8000 \mathrm{~g} / \mathrm{mol}\right)$, a

5 well-known antifouling material, was similarly investigated for protein adsorption by DLS

6 analysis. The hydrodynamic sizes $\left(\mathrm{D}_{\mathrm{h}}=5.48 \pm 0.10 \mathrm{~nm}(\mathrm{n}=3)\right)$, derived count rates and

7 correlograms of the PEG8000 (1 wt \%) and lysozyme (1wt\%) mixture also lie in between that of

$81 \mathrm{wt} \%$ PEG8000 $(5.84 \pm 0.40 \mathrm{~nm}(\mathrm{n}=3))$ and $1 \mathrm{wt} \%$ lysozyme $(4.69 \pm 0.25 \mathrm{~nm}(\mathrm{n}=3))$ in PBS

9 (Figure S40). These results support that the PEGylated polypeptoids do not adsorb appreciably to 10 lysozyme.
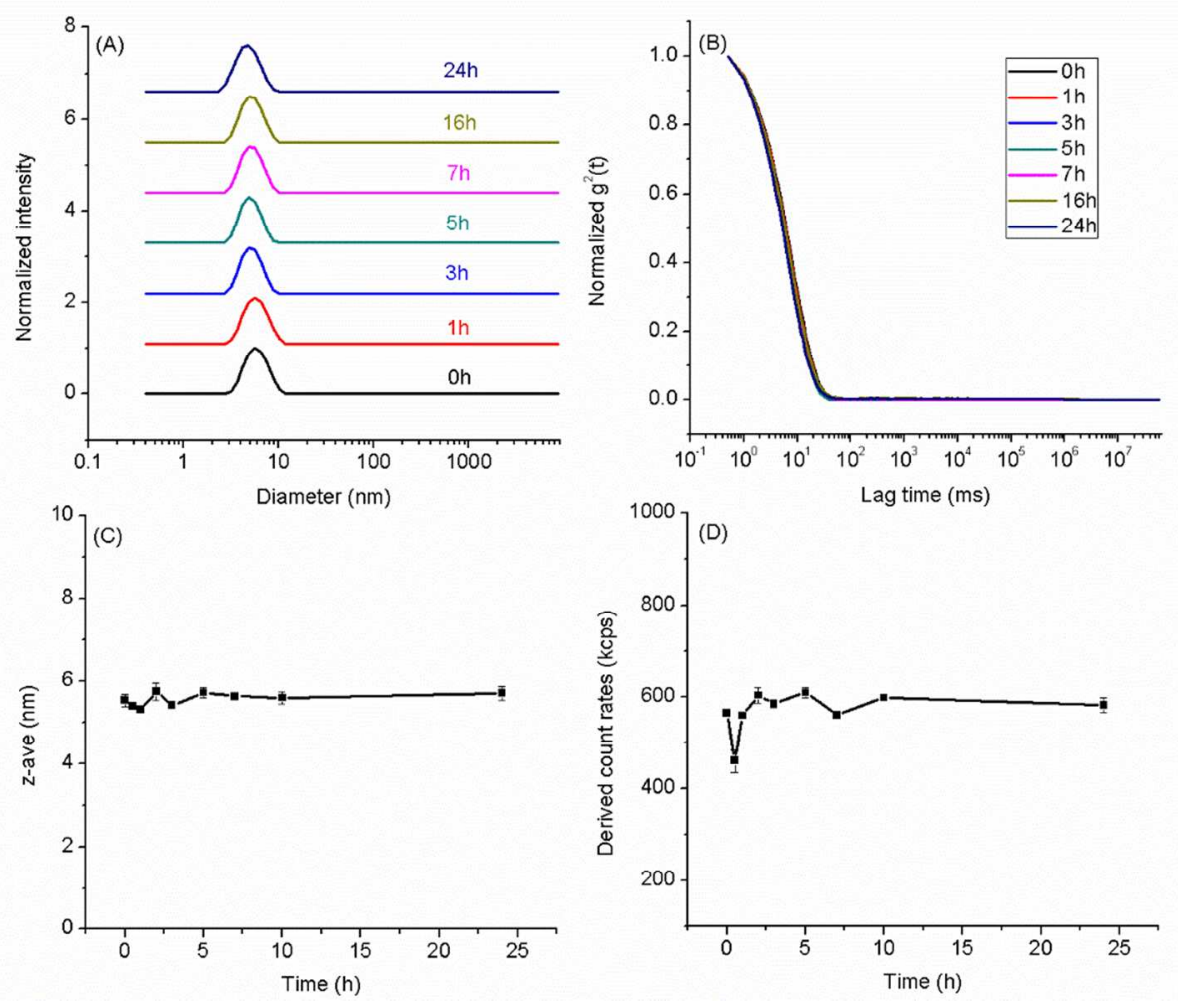
1 Figure 7. DLS analysis of mixture of $1 \mathrm{wt} \%$ lysozyme and $\mathrm{PNMeOEtG}_{106}$ in PBS:

2 hydrodynamic size distributions (A, C), correlograms (B) and derived count rates (D) up to $24 \mathrm{~h}$.

3 The error bars in (C) and (D) are the standard deviations of three measurements.
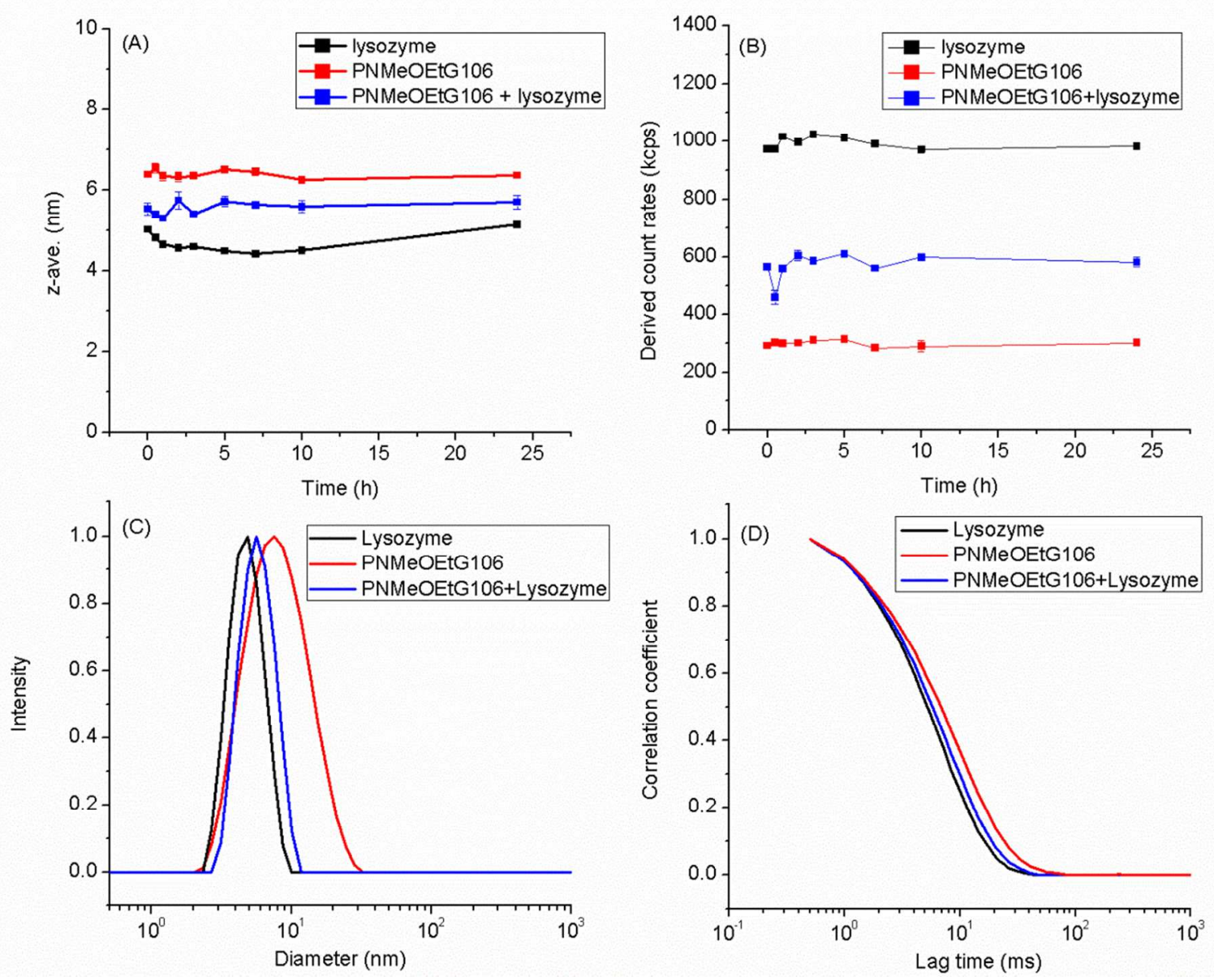

5 Figure 8. DLS analysis of mixture of $1 \mathrm{wt} \% \mathrm{PNMeOEtG}_{106}, 1 \mathrm{wt} \%$ lysozyme, $1 \mathrm{wt} \%$ lysozyme 6 and $1 \mathrm{wt} \% \mathrm{PNMeOEtG}_{106}$ in PBS: hydrodynamic size distributions (A) and derived count rates

7 (B) up to $24 \mathrm{~h}$; hydrodynamic size distributions (C) and correlograms (D) at $5 \mathrm{~h}$. The error bars in 8 (A) and (B) are the standard deviations of three measurements. 
1 studies in HEPES buffer. The data presented in Figure 9 is after background subtraction of the 2 HEPES buffer.
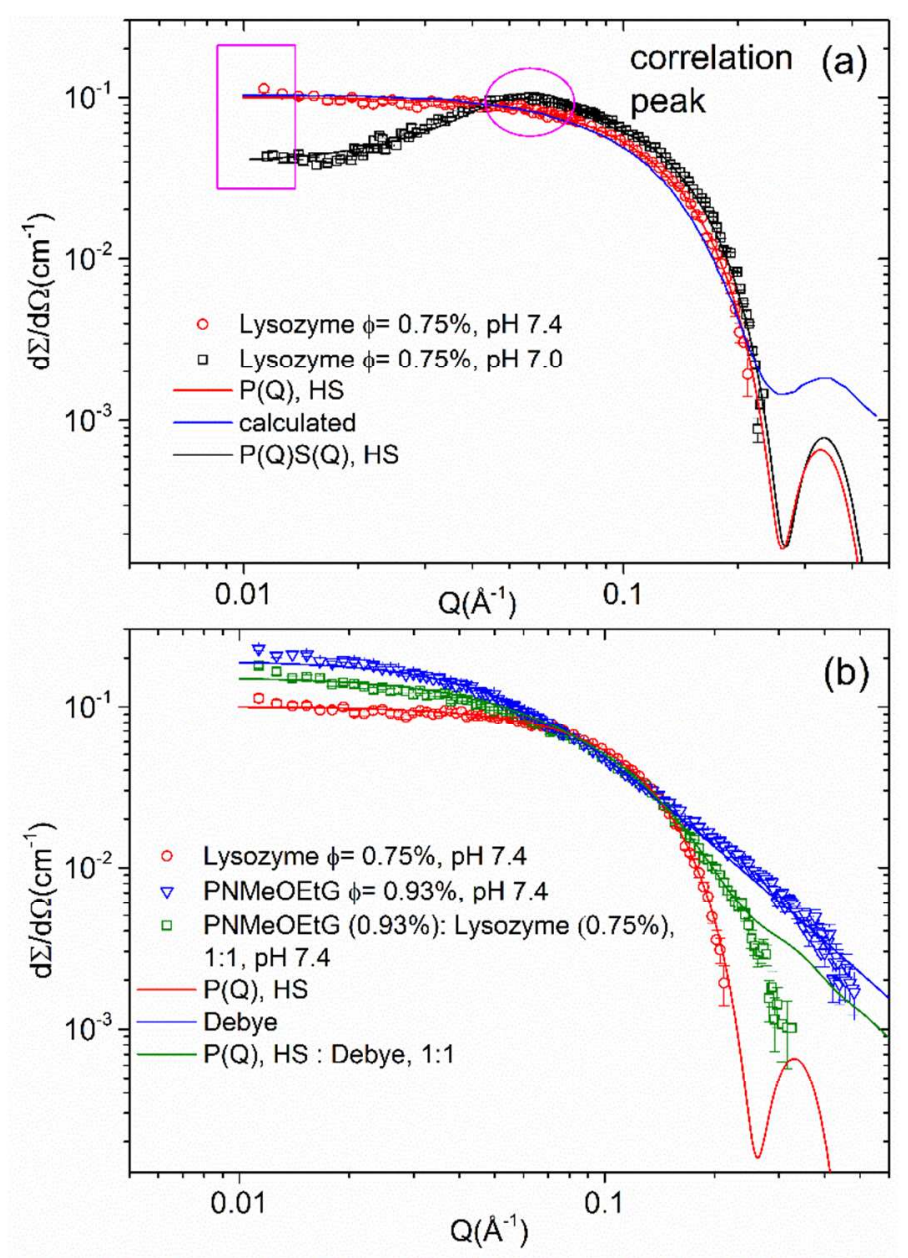

3

4 Figure 9. SANS diffraction pattern: (a) lysozyme in HEPES buffer for different pH values (pH 7.

5 4: $\circ$; $\mathrm{pH}$ 7.0: $\square$ ). The solid lines are the fits using equation (1): the red solid line (-) is the 6 lysozyme modelled using a hard sphere (HS) form factor $(\mathrm{P}(\mathrm{Q}), \mathrm{HS})$ for structure factor $\mathrm{S}(\mathrm{Q})=1$

7 at $\mathrm{pH} 7.4$; the blue solid line (-) is the modelled form factor calculated from the atomic 8 coordinates of the lysozyme; the black solid line (-) is the lysozyme modelled using a product 9 of HS form factor and a repulsive HS structure factor (percuss Yevick approximation) at $\mathrm{pH}$ 7.0. 10 (b) Comparison of the scattering pattern among lysozyme (०), polymer $(\mathrm{PNMeOEtG})(\nabla)$ and 
$1 \quad$ 1:1 lysozyme - polymer mixture ( $\square$ ) all at $\mathrm{pH}$ 7.4. The solid lines are the fits using equation (1)

$2(\mathrm{~S}(Q)=1)$ for HS $\mathrm{P}(Q)$ in red $(-)$, for Gaussian polymer coil (Debye) in blue $(-)$ and for $1: 1$

3 mixture of polymer and lysozyme in green $(-)$.

4

6

8

10

11

12

13

14

15

16

17

18

19

20

21

22

23

Figure 9(a) represents the SANS diffraction data for the lysozyme at $\mathrm{pH} 7.0$ and 7.4. The rectangular highlighted box at low $Q$ shows an increase in scattering, suggesting formation of aggregates or clusters (attractive interaction) for $\mathrm{pH} 7.4$ and less pronounce for $\mathrm{pH}$ 7.0. In addition, surprisingly unique to $\mathrm{pH} 7.0$, at $Q=0.057 \AA^{-1}$ there is an evolution of a correlation peak that indicates repulsive interaction. Following equation (1) the data at $\mathrm{pH} 7.4$ was modelled

(solid red line) using a hard sphere (HS) form factor $(\mathrm{P}(\mathrm{Q}), \mathrm{HS})$ for $S(Q)=1 .^{66}$ The data at $\mathrm{pH}$ 7.0 was modelled (solid black line) using a product of HS form factor and a repulsive HS structure factor (Percuss Yevick approximation). ${ }^{53-54}$ The modelled form factor is in good agreement with that calculated from the atomic coordinates of the lysozyme (Figure 9a, solid blue line). ${ }^{67-69}$ The HS form factor for the lysozyme yields a radius of $\mathrm{R}_{\mathrm{L}}=1.71 \pm 0.01 \mathrm{~nm}$ which is in agreement with the literature report. We did not find difference in size while modelling with an ellipsoidal form factor as was used by Shukla et al. ${ }^{69}$ The lysozyme contrast with respect to $\mathrm{D}_{2} \mathrm{O}$ is calculated to be, $\Delta \rho \sim 2.6 \times 10^{10} \mathrm{~cm}^{-2}$, for the density of $1.32 \mathrm{~g} / \mathrm{cm}^{3}{ }^{70}$ It should be noted that from the model fitting of the data at $\mathrm{pH} 7.0$ yield a HS $S(\mathrm{Q})$ interaction radius, $R_{\mathrm{C}}=4.85 \pm$ $0.02 \mathrm{~nm}$, which is $\sim 2.8$ times larger than $R_{\mathrm{L}}$. This suggests the formation of clusters as a result of lowering of the $\mathrm{pH}$ value (from 7.4 to 7.0 ) is responsible for the structure factor peak in Figure 9 (a). Formation of clusters was also reported first by Stradner et al. ${ }^{67}$ and later by Shukla et al., ${ }^{69}$ for lysozyme solutions. Stradner et al. ${ }^{67}$ also reported that the $\mathrm{S}(\mathrm{Q})$ peak position was found to be independent of the lysozyme concentration. The driving force for cluster formation in proteins is the balance between the short-range attraction and long range electrostatic repulsion. The net 
1 charge of the protein as known from the titration experiment is approximately $+8.5 e$ and $+8.0 \mathrm{e}$

2 for $\mathrm{pH} 7.0$ and 7.4 , respectively. ${ }^{71}$ Therefore decrease in $\mathrm{pH}$ causes an increase in the repulsive

3 interaction (protein surface charge) between the clusters that causes a sharp decrease in the

4 overall forward scattering intensity, $\frac{d \Sigma}{d \Omega}(Q \rightarrow 0)$, which is manifested as a structure factor

5 (correlation) peak seen in the data at $\mathrm{pH}$ 7.0. Following Stradner et al. ${ }^{67}$ we can argue that the

6 correlation peak reveals the distance between the clusters (cluster-cluster interaction length

$7 \quad 2 R_{C}$ ) but not the individual lysozyme molecules.

8 In Figure 9 (b) a comparison of the SANS pattern for a mixture of lysozyme and

9 PNMeOEtG polymer is presented. For the pure polymer the form factor was modelled using a 10 Debye function that describes a random Gaussian $\operatorname{coil}^{55}$ and the structure factor $S(Q)$ equals to 1 11 in equation 1. It yields a radius of gyration, $R_{\mathrm{g}}=2.62 \pm 0.02 \mathrm{~nm}$. The corresponding open square 12 data, represents the 1:1 mixture of the polymer and the lysozyme in a $\mathrm{pH} 7.4$ buffer solution. The 13 data can be modelled by calculating the 1:1 ratio of the scattering pattern obtained from the 14 Debye function for the polymer and the HS form factor for the lysozyme. This clearly supports 15 the absence of any interaction between the polymer and the lysozyme, resulting in the scattering 16 curve of the binary mixture a simple summation of the individual scattering component. It should 17 be noted that these are in contrast to the previous study on the solution mixture of haemoglobin 18 and PEO, where notable interaction between the protein and polymer was observed. ${ }^{72}$

19 Cytotoxicity study. The cytotoxicity of the PNMeOEtG polypeptoids was assessed using HEp2 20 cells by the MTT assay. PEG $(8000 \mathrm{~g} / \mathrm{mol})$, a gold standard for antifouling material, is used as a 21 positive control. The PNMeOEtG having different molecular weight $(3.26-11.1 \mathrm{~kg} / \mathrm{mol})$ showed 22 minimal cytotoxicity towards HEp2 cells with more than $90 \%$ cell viability in the $0.0625-1.0$ $23 \mathrm{mg} / \mathrm{mL}$ polymer concentration range (Figure 10). 


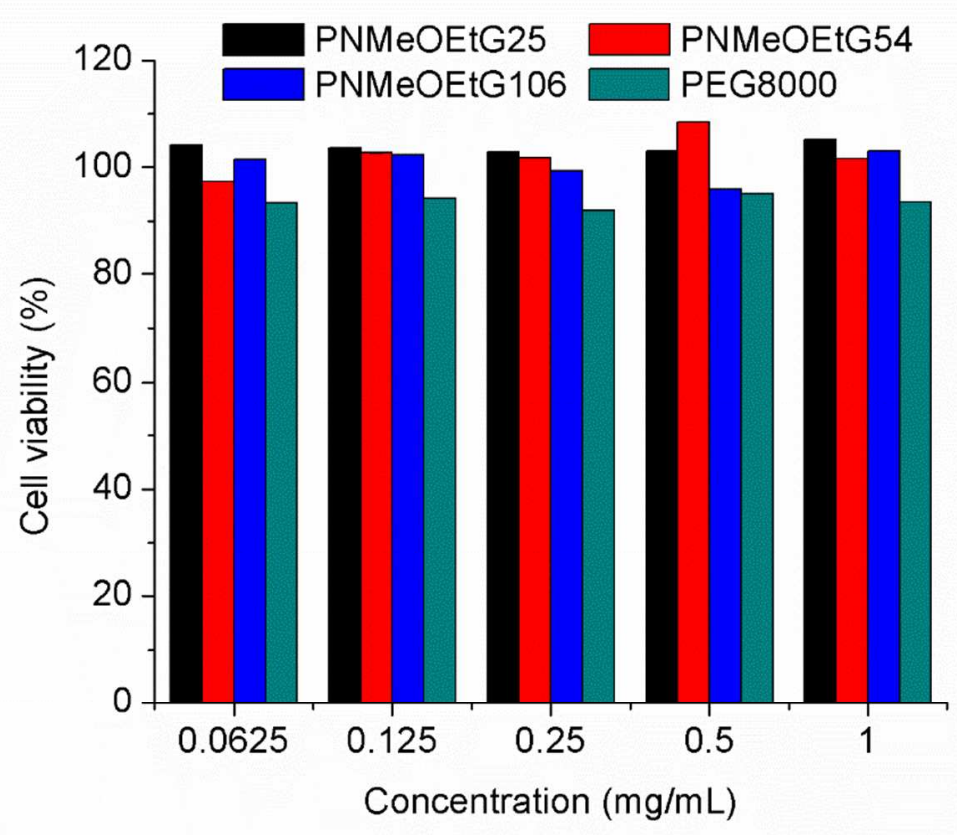

2 Figure 10. Cell viability study of PNMeOEtG polypeptoids compared to PEG (8000 Da). The

$3 \mathrm{DP}_{\mathrm{n}} \mathrm{s}$ listed in the figure were determined from NMR end-group analysis. The error bars in the

4 figure are the standard deviations of three measurements.

5 Conclusions. $N$ substituted $N$-carboxyanhydride monomers bearing oligomeric ethylene

6 glycol side chains $\left(\mathrm{Me}(\mathrm{OEt})_{\mathrm{n}}-\mathrm{NCA}(\mathrm{n}=1-3)\right.$ have been successfully synthesized in good yields.

7 Polymerization of $\left(\mathrm{Me}(\mathrm{OEt})_{\mathrm{n}}-\mathrm{NCA}(\mathrm{n}=1-3)\right.$ monomers using primary amine initiators proceeds

8 in a controlled manner, yielding the corresponding PEGylated polypeptoids $\left(\mathrm{PNMe}(\mathrm{OEt})_{\mathrm{n}} \mathrm{G}, \mathrm{n}=\right.$

9 1-3) having well-defined structures with controlled molecular weight in the $3.26-28.6 \mathrm{~kg} / \mathrm{mol}$ 10 range and narrow molecular distribution (PDI $=1.03-1.10)$. The resulting PEGylated

11 polypeptoids are amorphous with glass transition temperatures decreasing with increased 12 oligomeric ethylene glycol sidechain length. The PNMeOEtG polymers are highly water soluble 13 (solubility $>200 \mathrm{mg} / \mathrm{mL}$ at room temperature) and are minimally cytotoxic towards Hep2 cells. 14 DLS And SANS analysis of the aqueous solution containing a mixture of PNMeOEtG and 
1 lysozyme at $1 \mathrm{wt} \%$ concentration revealed minimal interactions between lysozyme and

2 PNMeOEtG in water, underscoring the potential of the PEGylated polypeptoids as promising

3 anti-fouling materials for biomedical and biotechnological applications.

\section{Supporting Information:}

$5 \quad{ }^{1} \mathrm{H}$ and ${ }^{13} \mathrm{C}\left\{{ }^{1} \mathrm{H}\right\}$ spectra for precursor of monomers, monomers and corresponding 6 PEGylated polypeptoids, SEC-DRI chromatograms of PEGylated polypeptoids, MALDI-TOF

7 MS spectra of PEGylated polypeptoids, TGA and DSC graphs of PEGylated polypeptoids, DLS

8 analysis of $1 \mathrm{wt} \%$ PNMeOEtG106 in PBS, DLS analysis of $1 \mathrm{wt} \%$ lysozyme in PBS, DLS

9 analysis of $1 \mathrm{wt} \%$ PEG8000 in PBS, DLS of the mixture of $1 \mathrm{wt} \%$ PEG8000 and $1 \mathrm{wt} \%$

10 lysozyme in PBS, SEC chromatograms and $M_{\mathrm{n}}$ and PDI data from polymerization of MeOEt-

11 NCA in toluene. This material is available free of charge via the Internet at http://pubs.acs.org

\section{Corresponding Author}

13 Email: dhzhang@1su.edu and gjschneider@1su.edu

$14 \quad$ Notes

15 The author declare no competing financial interest.

16 Acknowledgments

17 We would like to acknowledge Dr. Rafael Cueto for his assistance with the TGA 18 measurements. This work is supported by the National Science Foundation (CHE 0955820 and 19 CHE 1609447) and the Louisiana State University. The neutron scattering work conducted by 20 SG is supported by the U.S. Department of Energy under EPSCoR Grant No. DE-SC0012432 21 with additional support from the Louisiana Board of Regents. This work utilized facilities were 22 supported in part by the National Science Foundation under Agreement No. DMR-1508249. We 
acknowledge the support of the National Institute of Standards and Technology (NIST), U.S.

Department of Commerce, in providing the neutron research facilities used in this work.

\section{References}

1. Meyers, S. R.; Grinstaff, M. W. Biocompatible and Bioactive Surface Modifications for Prolonged in Vivo Efficacy. Chem. Rev. 2012, 112 (3), 1615-1632.

2. Horbett, T. A., Protein Adsorption on Biomaterials. In Biomaterials: Interfacial Phenomena and Applications, American Chemical Society: 1982; Vol. 199, pp 233-244.

3. Mojtaba, B.; Maryam, K.; Larry, D. U., Poly(Ethylene Glycol) and Poly(Carboxy Betaine) Based Nonfouling Architectures: Review and Current Efforts. In Proteins at Interfaces Iii State of the Art, American Chemical Society: 2012; Vol. 1120, pp 621-643.

4. Wei, Q.; Becherer, T.; Angioletti-Uberti, S.; Dzubiella, J.; Wischke, C.; Neffe, A. T.;

Lendlein, A.; Ballauff, M.; Haag, R. Protein Interactions with Polymer Coatings and Biomaterials. Angew. Chem. Int. Ed. 2014, 53 (31), 8004-8031.

5. Pertsin, A. J.; Grunze, M. Computer Simulation of Water near the Surface of Oligo(Ethylene Glycol)-Terminated Alkanethiol Self-Assembled Monolayers. Langmuir 2000, 16 (23), 8829-8841.

6. Chapman, R. G.; Ostuni, E.; Takayama, S.; Holmlin, R. E.; Yan, L.; Whitesides, G. M. Surveying for Surfaces That Resist the Adsorption of Proteins. J. Am. Chem. Soc. 2000, 122 (34), 8303-8304.

7. Ostuni, E.; Chapman, R. G.; Holmlin, R. E.; Takayama, S.; Whitesides, G. M. A Survey of Structure-Property Relationships of Surfaces That Resist the Adsorption of Protein. Langmuir 2001, 17 (18), 5605-5620.

8. Knop, K.; Hoogenboom, R.; Fischer, D.; Schubert, U. S. Poly(Ethylene Glycol) in Drug Delivery: Pros and Cons as Well as Potential Alternatives. Angew. Chem. Int. Ed. 2010, 49 (36), 6288-6308.

9. $\quad$ Romberg, B.; Metselaar, J. M.; Baranyi, L.; Snel, C. J.; Bünger, R.; Hennink, W. E.; Szebeni, J.; Storm, G. Poly(Amino Acid)S: Promising Enzymatically Degradable Stealth Coatings for Liposomes. Int. J. Pharm. 2007, 331 (2), 186-189.

10. Chelmowski, R.; Köster, S. D.; Kerstan, A.; Prekelt, A.; Grunwald, C.; Winkler, T.; Metzler-Nolte, N.; Terfort, A.; Wöll, C. Peptide-Based Sams That Resist the Adsorption of Proteins. J. Am. Chem. Soc. 2008, 130 (45), 14952-14953.

11. Engler, A. C.; Ke, X.; Gao, S.; Chan, J. M. W.; Coady, D. J.; Ono, R. J.; Lubbers, R.; Nelson, A.; Yang, Y. Y.; Hedrick, J. L. Hydrophilic Polycarbonates: Promising Degradable Alternatives to Poly(Ethylene Glycol)-Based Stealth Materials. Macromolecules 2015, 48 (6), 1673-1678.

12. Konradi, R.; Pidhatika, B.; Mühlebach, A.; Textor, M. Poly-2-Methyl-2-Oxazoline: A Peptide-Like Polymer for Protein-Repellent Surfaces. Langmuir 2008, 24 (3), 613-616.

39 13. Pidhatika, B.; Möller, J.; Benetti, E. M.; Konradi, R.; Rakhmatullina, E.; Mühlebach, A.; 40 Zimmermann, R.; Werner, C.; Vogel, V.; Textor, M. The Role of the Interplay between Polymer 
Architecture and Bacterial Surface Properties on the Microbial Adhesion to Polyoxazoline-Based Ultrathin Films. Biomaterials 2010, 31 (36), 9462-9472.

14. Hoogenboom, R. Poly(2-Oxazoline)S: A Polymer Class with Numerous Potential Applications. Angew. Chem. Int. Ed. 2009, 48 (43), 7978-7994.

15. Teare, D. O. H.; Schofield, W. C. E.; Garrod, R. P.; Badyal, J. P. S. Poly(NAcryloylsarcosine Methyl Ester) Protein-Resistant Surfaces. J. Phys. Chem. B 2005, 109 (44), 20923-20928.

16. Huber, D. L.; Manginell, R. P.; Samara, M. A.; Kim, B.-I.; Bunker, B. C. Programmed Adsorption and Release of Proteins in a Microfluidic Device. Science 2003, 301 (5631), 352-354. 17. Yang, J.; Zhang, M.; Chen, H.; Chang, Y.; Chen, Z.; Zheng, J. Probing the Structural Dependence of Carbon Space Lengths of Poly(N-Hydroxyalkyl Acrylamide)-Based Brushes on Antifouling Performance. Biomacromolecules 2014, 15 (8), 2982-2991.

18. Chan, J. M. W.; Ke, X.; Sardon, H.; Engler, A. C.; Yang, Y. Y.; Hedrick, J. L.

Chemically Modifiable N-Heterocycle-Functionalized Polycarbonates as a Platform for Diverse Smart Biomimetic Nanomaterials. Chem. Sci. 2014, 5 (8), 3294-3300.

19. Yang, W.; Sundaram, H. S.; Ella, J.-R.; He, N.; Jiang, S. Low-Fouling Electrospun Plla Films Modified with Zwitterionic Poly(Sulfobetaine Methacrylate)-Catechol Conjugates. Acta Biomater. 2016, 40, 92-99.

20. Jeong, J. H.; Song, S. H.; Lim, D. W.; Lee, H.; Park, T. G. DNA Transfection Using Linear Poly(Ethylenimine) Prepared by Controlled Acid Hydrolysis of Poly(2-Ethyl-2Oxazoline). J. Controlled Release 2001, 73 (2-3), 391-399.

21. Wang, C.-H.; Fan, K.-R.; Hsiue, G.-H. Enzymatic Degradation of Plla-Peoz-Plla Triblock Copolymers. Biomaterials 2005, 26 (16), 2803-2811.

22. Duracher, D.; Veyret, R.; Elaïssari, A.; Pichot, C. Adsorption of Bovine Serum Albumin Protein onto Amino-Containing Thermosensitive Core-Shell Latexes. Polym. Int. 2004, 53 (5), 618-626.

23. Miller, S. M.; Simon, R. J.; Ng, S.; Zuckermann, R. N.; Kerr, J. M.; Moos, W. H. Proteolytic Studies of Homologous Peptide and N-Substituted Glycine Peptoid Oligomers. Biorg. Med. Chem. Lett. 1994, 4 (22), 2657-2662.

24. Miller, S. M.; Simon, R. J.; Ng, S.; Zuckermann, R. N.; Kerr, J. M.; Moos, W. H. Comparison of the Proteolytic Susceptibilities of Homologous L-Amino Acid, D-Amino Acid, and N-Substituted Glycine Peptide and Peptoid Oligomers. Drug Dev. Res. 1995, 35 (1), 20-32. 25. Patch, J. A.; Barron, A. E. Mimicry of Bioactive Peptides Via Non-Natural, SequenceSpecific Peptidomimetic Oligomers. Curr. Opin. Chem. Biol. 2002, 6 (6), 872-877.

26. Latham, P. W. Therapeutic Peptides Revisited. Nat. Biotechnol. 1999, 17 (8), 755-757. 27. Hardesty, J. O.; Cascão-Pereira, L.; Kellis, J. T.; Robertson, C. R.; Frank, C. W. Enzymatic Proteolysis of a Surface-Bound A-Helical Polypeptide. Langmuir 2008, 24 (24), 13944-13956.

28. De Marre, A.; Hoste, K.; Bruneel, D.; Schacht, E.; De Schryver, F. Synthesis, Characterization, and in Vitro Biodegradation of Poly(Ethylene Glycol) Modified Poly[5n-(2Hydroxyethyl-L-Glutamine]. J. Bioact. Compatible Polym. 1996, 11 (2), 85-99.

42 29. Gabizon, A. P., D. Liposome Formulations with Prolonged Circulation Time in Blood 43 and Enhanced Uptake by Tumors. Proc. Natl. Acad. Sci. U.S.A. 1988, 85 (18), 6949-6953.

44 30. Friend, D. R.; Pangburn, S. Site-Specific Drug Delivery. Med. Res. Rev. 1987, 7 (1), $53-$ 45106. 
31. Tempelaar, S.; Mespouille, L.; Coulembier, O.; Dubois, P.; Dove, A. P. Synthesis and Post-Polymerisation Modifications of Aliphatic Poly(Carbonate)S Prepared by Ring-Opening Polymerisation. Chem. Soc. Rev. 2013, 42 (3), 1312-1336.

32. Pascual, A.; Tan, J. P. K.; Yuen, A.; Chan, J. M. W.; Coady, D. J.; Mecerreyes, D.; Hedrick, J. L.; Yang, Y. Y.; Sardon, H. Broad-Spectrum Antimicrobial Polycarbonate Hydrogels with Fast Degradability. Biomacromolecules 2015, 16 (4), 1169-1178.

33. Wang, H.-F.; Su, W.; Zhang, C.; Luo, X.-h.; Feng, J. Biocatalytic Fabrication of FastDegradable, Water-Soluble Polycarbonate Functionalized with Tertiary Amine Groups in Backbone. Biomacromolecules 2010, 11 (10), 2550-2557.

34. Zhang, Z.; Kuijer, R.; Bulstra, S. K.; Grijpma, D. W.; Feijen, J. The in Vivo and in Vitro Degradation Behavior of Poly(Trimethylene Carbonate). Biomaterials 2006, 27 (9), 1741-1748.

35. Zhang, D.; Lahasky, S. H.; Guo, L.; Lee, C.-U.; Lavan, M. Polypeptoid Materials: Current Status and Future Perspectives. Macromolecules 2012, 45 (15), 5833-5841.

36. Barron, A. E.; Zuckerman, R. N. Bioinspired Polymeric Materials: In-between Proteins and Plastics. Curr. Opin. Chem. Biol. 1999, 3 (6), 681-687.

37. Lahasky, S. H.; Hu, X.; Zhang, D. Thermoresponsive Poly(A-Peptoid)S: Tuning the Cloud Point Temperatures by Composition and Architecture. ACS Macro Letters 2012, 1 (5), 580-584.

38. Fetsch, C.; Flecks, S.; Gieseler, D.; Marschelke, C.; Ulbricht, J.; van Pée, K.-H.; Luxenhofer, R. Self-Assembly of Amphiphilic Block Copolypeptoids with C2-C5 Side Chains in Aqueous Solution. Macromol. Chem. Phys. 2015, 216 (5), 547-560.

39. Xuan, S.; Lee, C.-U.; Chen, C.; Doyle, A. B.; Zhang, Y.; Guo, L.; John, V. T.; Hayes, D.; Zhang, D. Thermoreversible and Injectable Abc Polypeptoid Hydrogels: Controlling the Hydrogel Properties through Molecular Design. Chem. Mater. 2016, 28 (3), 727-737.

40. Li, A.; Zhang, D. Synthesis and Characterization of Cleavable Core-Cross-Linked Micelles Based on Amphiphilic Block Copolypeptoids as Smart Drug Carriers.

Biomacromolecules 2016, 17 (3), 852-861.

41. Ulbricht, J.; Jordan, R.; Luxenhofer, R. On the Biodegradability of Polyethylene Glycol, Polypeptoids and Poly(2-Oxazoline)S. Biomaterials 2014, 35 (17), 4848-4861.

42. Sun, J.; Zuckermann, R. N. Peptoid Polymers: A Highly Designable Bioinspired Material. ACS Nano 2013, 7 (6), 4715-4732.

43. Luxenhofer, R.; Fetsch, C.; Grossmann, A. Polypeptoids: A Perfect Match for Molecular Definition and Macromolecular Engineering? J. Polym. Sci., Part A: Polym. Chem. 2013, 51 (13), 2731-2752.

44. Zuckermann, R. N. Peptoid Origins. Pep. Sci. 2011, 96 (5), 545-555.

45. Secker, C.; Brosnan, S. M.; Luxenhofer, R.; Schlaad, H. Poly(A-Peptoid)S Revisited: Synthesis, Properties, and Use as Biomaterial. Macromol. Biosci. 2015, 15 (7), 881-891. 46. $\quad$ Lau, K. H. A.; Ren, C.; Sileika, T. S.; Park, S. H.; Szleifer, I.; Messersmith, P. B. Surface-Grafted Polysarcosine as a Peptoid Antifouling Polymer Brush. Langmuir 2012, 28 (46), 16099-16107.

47. Lau, K. H. A.; Ren, C.; Park, S. H.; Szleifer, I.; Messersmith, P. B. An ExperimentalTheoretical Analysis of Protein Adsorption on Peptidomimetic Polymer Brushes. Langmuir 2011, 28 (4), 2288-2298.

48. Statz, A. R.; Barron, A. E.; Messersmith, P. B. Protein, Cell and Bacterial Fouling Resistance of Polypeptoid-Modified Surfaces: Effect of Side-Chain Chemistry. Soft Matter 2008, 4 (1), 131-139. 
49. Schneider, M.; Fetsch, C.; Amin, I.; Jordan, R.; Luxenhofer, R. Polypeptoid Brushes by Surface-Initiated Polymerization of N-Substituted Glycine N-Carboxyanhydrides. Langmuir 2013, 29 (23), 6983-6988.

50. Sun, J.; Stone, G. M.; Balsara, N. P.; Zuckermann, R. N. Structure-Conductivity

Relationship for Peptoid-Based Peo-Mimetic Polymer Electrolytes. Macromolecules 2012, 45 (12), 5151-5156.

51. Frisken, B. J. Revisiting the Method of Cumulants for the Analysis of Dynamic LightScattering Data. Appl. Opt. 2001, 40 (24), 4087-4091.

52. Gupta, S.; Camargo, M.; Stellbrink, J.; Allgaier, J.; Radulescu, A.; Lindner, P.; Zaccarelli, E.; Likos, C. N.; Richter, D. Dynamic Phase Diagram of Soft Nanocolloids. Nanoscale 2015, 7 (33), 13924-13934.

53. Kinning, D. J.; Thomas, E. L. Hard-Sphere Interactions between Spherical Domains in Diblock Copolymers. Macromolecules 1984, 17 (9), 1712-1718.

54. Percus, J. K.; Yevick, G. J. Analysis of Classical Statistical Mechanics by Means of Collective Coordinates. Phys. Rev. 1958, 110 (1), 1-13.

55. Debye, P. Molecular-Weight Determination by Light Scattering. J. Phys. Colloid. Chem. 1947, 51 (1), 18-32.

56. Xuan, S.; Zhao, N.; Zhou, Z.; Fronczek, F. R.; Vicente, M. G. H. Synthesis and in Vitro Studies of a Series of Carborane-Containing Boron Dipyrromethenes (Bodipys). J. Med. Chem. 2016, 59 (5), 2109-2117.

57. Robinson, J. W.; Secker, C.; Weidner, S.; Schlaad, H. Thermoresponsive Poly(N-C3 Glycine)S. Macromolecules 2013, 46 (3), 580-587.

58. Guo, L.; Zhang, D. Cyclic Poly(A-Peptoid)S and Their Block Copolymers from NHeterocyclic Carbene-Mediated Ring-Opening Polymerizations of N-Substituted NCarboxylanhydrides. J. Am. Chem. Soc. 2009, 131 (50), 18072-18074.

59. Arbe, A.; Genix, A. C.; Colmenero, J.; Richter, D.; Fouquet, P. Anomalous Relaxation of Self-Assembled Alkyl Nanodomains in High-Order Poly(N-Alkyl Methacrylates). Soft Matter 2008, 4 (9), 1792-1795.

60. Gerstl, C.; Schneider, G. J.; Fuxman, A.; Zamponi, M.; Frick, B.; Seydel, T.; Koza, M.; Genix, A. C.; Allgaier, J.; Richter, D.; Colmenero, J.; Arbe, A. Quasielastic Neutron Scattering Study on the Dynamics of Poly(Alkylene Oxide)S. Macromolecules 2012, 45 (10), 4394-4405.

61. Moreno, A. J.; Arbe, A.; Colmenero, J. Structure and Dynamics of Self-Assembled Comb Copolymers: Comparison between Simulations of a Generic Model and Neutron Scattering Experiments. Macromolecules 2011, 44 (6), 1695-1706.

62. Arbe, A.; Genix, A. C.; Arrese-Igor, S.; Colmenero, J.; Richter, D. Dynamics in Poly(NAlkyl Methacrylates): A Neutron Scattering, Calorimetric, and Dielectric Study.

Macromolecules 2010, 43 (6), 3107-3119.

63. Gerstl, C.; Schneider, G. J.; Pyckhout-Hintzen, W.; Allgaier, J.; Richter, D.; Alegría, A.; Colmenero, J. Segmental and Normal Mode Relaxation of Poly(Alkylene Oxide)S Studied by Dielectric Spectroscopy and Rheology. Macromolecules 2010, 43 (11), 4968-4977.

64. Fetsch, C.; Luxenhofer, R. Thermal Properties of Aliphatic Polypeptoids. Polymers 2013, $5(1), 112$.

65. Biswas, C. S.; Patel, V. K.; Vishwakarma, N. K.; Tiwari, V. K.; Maiti, B.; Maiti, P.; Kamigaito, M.; Okamoto, Y.; Ray, B. Effects of Tacticity and Molecular Weight of Poly(NIsopropylacrylamide) on Its Glass Transition Temperature. Macromolecules 2011, 44 (14), 58225824. 
1 66. Gupta, S.; Fischer, J. K. H.; Lunkenheimer, P.; Loidl, A.; Novak, E.; Jalarvo, N.; Ohl, M. 2 Effect of Adding Nanometre-Sized Heterogeneities on the Structural Dynamics and the Excess 3 Wing of a Molecular Glass Former. Sci. Rep. 2016, 6, 35034.

$4 \quad 67 . \quad$ Stradner, A.; Sedgwick, H.; Cardinaux, F.; Poon, W. C. K.; Egelhaaf, S. U.;

5 Schurtenberger, P. Equilibrium Cluster Formation in Concentrated Protein Solutions and 6 Colloids. Nature 2004, 432 (7016), 492-495.

7 68. Diamond, R. Real-Space Refinement of the Structure of Hen Egg-White Lysozyme. $J$. 8 Mol. Biol. 1974, 82 (3), 371-391.

9 69. Shukla, A.; Mylonas, E.; Di Cola, E.; Finet, S.; Timmins, P.; Narayanan, T.; Svergun, D. 10 I. Absence of Equilibrium Cluster Phase in Concentrated Lysozyme Solutions. Proc. Natl. Acad. 11 Sci. 2008, 105 (13), 5075-5080.

12 70. Narayanan, J.; Liu, X. Y. Protein Interactions in Undersaturated and Supersaturated 13 Solutions: A Study Using Light and X-Ray Scattering. Biophys. J. 2003, 84 (1), 523-532. 14 71. Tanford, C.; Roxby, R. Interpretation of Protein Titration Curves. Application to 15 Lysozyme. Biochemistry 1972, 11 (11), 2192-2198.

16 72. Gupta, S.; Biehl, R.; Sill, C.; Allgaier, J.; Sharp, M.; Ohl, M.; Richter, D. Protein 17 Entrapment in Polymeric Mesh: Diffusion in Crowded Environment with Fast Process on Short 18 Scales. Macromolecules 2016, 49 (5), 1941-1949. 
1

2

3 Well-defined PEGylated polypeptoids as protein-resistant polymers 4

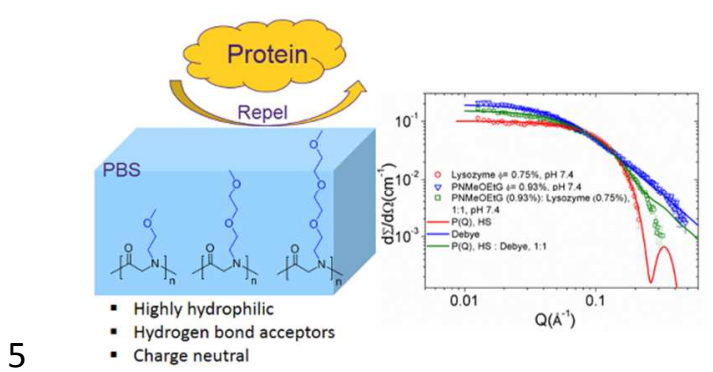

19

20

21

22

23

24

25

26

27

28

32

33

34

35

36

37

38

39

40

41

42

43

44

45

46

47

48

49

50

51

52

53

54

55

56 
Synthesis and Characterization of Well-defined PEGylated Polypeptoids as Protein-resistant Polymers + Sunting Xuan, Sudipta Gupta, Xin Li, Markus Bleuel, Gerald J. Schneider and Donghui Zhang* $63 \times 35 \mathrm{~mm}(220 \times 220 \mathrm{DPI})$ 